\title{
Cognitive and Contextual Factors in the Emergence of Diverse Belief Systems: Creation versus Evolution
}

\author{
E. Margaret Evans
}

\section{University of Toledo}

The emergence and distribution of beliefs about the origins of species is investigated in Christian fundamentalist and nonfundamentalist school communities, with participants matched by age, educational level, and locale. Children $(n=185)$ and mothers $(n=92)$ were questioned about animate, inanimate, and artifact origins, and children were asked about their interests and natural-history knowledge. Preadolescents, like their mothers, embraced the dominant beliefs of their community, creationist or evolutionist; 8 - to 10 -year-olds were exclusively creationist, regardless of community of origin; 5- to 7-year-olds in fundamentalist schools endorsed creationism, whereas nonfundamentalists endorsed mixed creationist and spontaneous generationist beliefs. Children's natural-history knowledge and religious interest predicted their evolutionist and creationist beliefs, respectively, independently of parent beliefs. It is argued that this divergent developmental pattern is optimally explained with a model of constructive interactionism: Children generate intuitive beliefs about origins, both natural and intentional, while communities privilege certain beliefs and inhibit others, thus engendering diverse belief systems. ( 2001 Academic Press

Key Words: analogy; conceptual development; constructivism; context; creationist; culture; essentialism; evolutionist; knowledge; naive biology, naive psychology; teleology.

Support for the research was provided in part by a Spencer Dissertation Fellowship. The writing was supported by a National Academy of Education Spencer Postdoctoral Fellowship. Portions of this research have been presented at the meetings of the Society for Research in Child Development in Indianapolis, Indiana (March 1995), and Washington (April 1997) and of the Jean Piaget Society in Santa Monica (June 1997). I gratefully acknowledge the help and advice of Henry Buchtel, Laura Klenk, Susan Gelman, Lawrence Hirschfeld, Harold Stevenson and, in particular, Henry Wellman. Justin Barrett, Henry Buchtel, Joan Miller and two anonymous reviewers provided insightful criticisms of earlier versions of the manuscript. I am especially indebted to the parents, children, and teachers from three midwestern Christian Fundamentalist schools and to families in nearby rural and suburban areas for their participation in the study. This research would not have been possible without the help of interviewers Cindy Andress and Susan Stewart and the artwork of Cindy Andress, who created the stimuli. Correspondence and requests for reprints should be addressed to E. Margaret Evans, Department of Psychology, University of Toledo, 2801 W. Bancroft Street, Toledo, Ohio 436063390. E-mail: mevans@uoft02.utoledo.edu 
The ideological banners raised by supporters at either end of the creationist-evolutionist debate mark extreme positions of one of the most strident of arguments about the nature of science in the 20th century. Scientific creationism has been declared an oxymoron (Numbers, 1992), and creationists have been viewed as a group of "ignorant fools" who are "abusing science", (Godfrey, 1984). Creationist scientists have been equally caustic, dismissing evolutionary explanations as mere theory (Cavanaugh, 1985) and accusing evolution scientists of Satanism: "Satan himself is the originator of the concept of evolution' (Morris, 1975, cited in Kehoe, 1995). Distortion of an opponent's position is typical of "partisans to ideological disputes" (Keltner \& Robinson, 1996, p. 105) but behind the rhetoric lies an interesting question, to be examined in this study: How can both of these incompatible beliefs receive such widespread support? The present paper examines the natural history of these ideas, their emergence and distribution in a population of school-age children.

The dissemination of evolutionist and creationist beliefs in the population at large, it will be argued, is a testament not only to their public availability but also to their cognitive appeal (see Shore, 1996; Sperber, 1996; Strauss \& Quinn, 1997). The claim that creationist ideas are intuitively plausible while Darwinian concepts are intuitively opaque (e.g., Dawkins, 1987) suggests that cognitive constraints facilitate or limit the adoption of these explanations. On the other hand, it could also be claimed that the spread of such beliefs is simply a function of social forces. By charting the emergence of beliefs about origins in children from families where these beliefs are endorsed to different degrees such as Christian fundamentalist and comparable nonfundamentalist families, these competing claims can be examined in detail. To provide a context for interpreting the empirical findings a brief background to the ideological dispute will first be given. This will then be followed by a summary of some recent theoretical and empirical approaches that provide a rationale for the various measures and analyses employed in the empirical study.

\section{EVOLUTIONISTS AND CREATIONISTS}

Although evolution science and creation science are both 20th-century products, both have their roots in earlier controversies about the nature of biological kinds (e.g., Evans, 2000b; Mayr, 1982; Numbers, 1992). The cornerstone of modern biological explanation is evolutionary science, which arises from the synthesis of Darwinian theory and Mendelian genetics (Mayr, 1997); its central tenet is that all species, including the human, have a common descent extending over millions of years, and that distinct species arise through natural adaptive processes. In the theistic form of evolution science, embraced in some form by most Western religions, evolution is accepted as a valid scientific truth, but the originator of the process is considered to be 
a Supreme Being. In contrast, creation science, which receives its strongest support from Christian fundamentalism, holds to the biblical dictum that each biological kind or species was created individually by God about 6000 years ago: Biblical literalism (Numbers, 1992). A cornerstone of this world view is the immutability of species; new kinds could be created by God but never by natural means (Kehoe, 1995). Essentialistic explanations of this type, though, do allow for an inbuilt God-given capacity for limited change within a species, which permits some diversity in intraspecies phenotypes (Morris \& Parker, 1982).

Modern creation science owes its resurgence to a series of influential books by Christian Fundamentalists John C. Whitcomb and Henry M. Morris, published in the 1960s and 1970s. In these books the Noachim Flood is invoked to explain the fossil record and flood geology to explain the geological column (Kehoe, 1995; Numbers, 1992). The translation of this creationist literature into many languages fostered the rebirth and subsequent spread of creationist beliefs across the industrialized world (Cavanaugh, 1985). Within the United States, creationist and evolutionist beliefs are almost evenly distributed in the population at large, though there are regional variations (Cavanaugh, 1985; Miller, 1987; Numbers, 1992). Although those with a college education are somewhat less likely then those with only a high school education to hold creationist beliefs (Miller, 1987), such beliefs are, in general, remarkably resistant to instruction. Thirty-eight percent of undergraduates who had taken relevant courses in anthropology, for example, still held that the Garden of Eden was the origin of human life (Almquist \& Cronin, 1988). However, students with creationist beliefs are in general no more antiscientific than the rest of the undergraduate population, nor are they any more likely to believe in the paranormal (Harrold, Eve, \& Goede, 1995; Numbers, 1992).

In contrast to creationist ideas, modern evolutionary explanations, in particular Darwinian natural selection, appear to be very difficult to grasp (e.g., Ferrari \& Chi, 1998; Greene, 1990; Samarapungavan \& Wiers, 1997). Students from a variety of backgrounds, including school-age pupils, undergraduates, and even advanced biology and medical students, often default to a form of "Lamarckian" theorizing to explain adaptive change in species. The crux of the problem seems to be that natural selection requires students to accept strongly counterintuitive notions concerning random change and variation occurring at the level of a population. In spite of focused instruction (e.g., Bishop \& Anderson, 1990), such students are more likely to believe in the inheritance of acquired characteristics, that is that changes in an animal population result from individual adaptations to novel environmental conditions, which are then passed on to offspring. (The giraffe, for example, stretches its neck to reach high vegetation; its offspring inherit this characteristic.) It took the genius of Lamarck to theorize that such a mechanism could give rise to different species. It is not clear from the research on students' 
conceptions whether they reason that new kinds arise in this manner, or consider that what emerge are different versions of the same kind. Unlike Darwinian theory such explanations tend to be teleological in nature, in that they invoke adaptation as a solution to the needs and purposes of individual organisms (Evans, 2000b; Mayr, 1982). In contrast to that of creationist explanation, Lamarck's notion of teleology or purpose is dissociated from that of intention or desire, insofar as he eschewed anything other than material explanations (e.g., fluid dynamics) in his efforts to explain the apparent goaldirectedness of organisms (Atran, 1990; Gould, 1999). ${ }^{1}$

\section{SOURCE ANALOGIES FOR THE ORIGINS OF SPECIES}

When reasoning about an ill-defined or novel problem, such as the origins of species, scientists, theologians, and lay-people alike resort to analogy, which makes the unfamiliar known (Holyoak \& Thagard, 1995). Analogical reasoning is ubiquitous and appears to underlie many problem-solving capacities including the generation of explanation. A good source analog should match its target (i.e., the novel problem) in terms of feature similarity, structural relations, and purpose, which are hypothesized to act synergistically to constrain its use (Holyoak \& Thagard, 1995). By the time they are in elementary school, children are competent analogical reasoners, provided the source analog is grounded in familiar domains of knowledge (Gentner \& Rattermann, 1991; Goswami, Leevers, Pressley \& Wheelwright, 1998). Accordingly, elementary school children should be capable of constructing explanations for the origins of living beings without direct adult tutoring, at least to the extent that the source analogs cognitively available to them facilitate such constructions.

From the above description of the ideological dispute, two distinct theories about the origins of species are clearly identifiable in the population at large, namely creation and evolution. However, there is a third version, spontaneous generation, the idea that "living beings could arise from non-living matter' (Roger, 1986). Spontaneous generation was a feature of early Greek thought (Mayr, 1982), though it reappears in various guises over the centuries. Of the three versions, the creation story is the only one that overtly invokes an intentional and purposeful being; the others are naturalistic and nonintentional.

Many have speculated that the source analogy for creationism is human action (e.g., Guthrie, 1993; Holyoak \& Thagard, 1995; Piaget, 1929). There has been little empirical research on the topic but findings to date seem persuasive. For example, while most would claim that God has special powers,

${ }^{1}$ Lamarck, however, did credit God with the establishment of eternal living forms. For reasons of space the complexity of Lamarck's position cannot be conveyed here, but see Atran (1990) for a detailed exposition. 
on a recall task for stories in which God was depicted as all-powerful and all-knowing many undergraduates defaulted to a view of God as a human with limited capacities (Barrett \& Keil, 1996). If creationism is rooted in human experience then developmentally one might expect younger children to conflate God and human, with God depicted as an all-powerful parent. On the basis of interviews with children of different ages, Piaget (1929, pp. 356-385) concluded that children are able to distinguish between the powers of God and those of the human only after they understand the limitations of human (parent) capacities, which happens around the early to midelementary school years (see also Evans \& Gelman, 2001). More recent conceptualizations of children's intuitive beliefs view the latter as naive theories focused on specific ontological domains (e.g., Wellman \& Gelman, 1998). Numerous studies in this constructivist mode indicate that by the late preschool years children's understanding of their fellow humans, that is, children's naive psychology or theory of mind, is relatively advanced when compared to that of adults (Carey, 1985; Wellman \& Gelman, 1998). Findings such as these indicate a firm basis for a source analogy from which children could construct an understanding of creation, with God as a special kind of human with the power to create living beings the way humans make artifacts. This is a version of the classic argument from design (e.g., Dawkins, 1987; Holyoak \& Thagard, 1995).

In contrast to the difficulties of learning Darwinian concepts, the idea of inheriting acquired features appears to be intuitive, found from the "ancients to the nineteenth century" (Mayr, 1982) and even in present day preschoolers (Springer \& Keil, 1989). This suggests that children's intuitive ontologies might reference a natural mechanism, the inheritance of acquired features, which, even though incorrect, could be employed to explain the creation of new species. However, there is a crucial corollary: children must also accept the premise that members of a kind can change in a fundamental way. This premise, though, is unlikely to be a part of young children's repertoire of intuitive explanations, as it requires the overturning of their strongly held essentialist beliefs in the immutability of living beings (Gelman, Coley, \& Gottfried, 1994; Gelman \& Hirschfeld, 1999; Keil, 1989; Mayr, 1991). Because of their staunch essentialism, preschool and early-to-mid elementary school children would be unlikely to endorse any kind of natural explanation that involves species transformations. Nevertheless, one may ask whether there are any circumstances under which children might be induced to revise their implicit beliefs in the stability of species.

The intuitive basis for the claim that the inheritance of acquired characteristics could be a mechanism of species creation may arise from two source analogies. The first is the cultural transmission of knowledge. The second is gained from direct exposure to the natural world, and is probably more appropriate as an analogy. Observers of nature are routinely confronted with evidence of change in the characteristics of an animal population over brief 
periods of time, such as seasonal change (feather color) and metamorphosis (caterpillar/butterfly). Moreover, fossil knowledge along with examples of adaptation provided the material evidence that convinced scientists of the validity of evolutionary claims (Mayr, 1982). This analysis suggests that children's essentialist beliefs might be able to be modified by exposure to the fossil evidence or to evidence that animal populations apparently acquire new adaptive features in response to environmental change (dynamic adaptation: Evans, 2000b).

For spontaneous generation, the obvious source analogy could also be derived from direct experience of the natural world. Consider that after a spring thaw or a rainy period new life apparently spontaneously emerges from the earth. Although it preexisted in embryonic forms such as seeds or eggs, this might not be obvious to the casual observer. Unlike Lamarckian evolution or creation, spontaneous generation explanations are nonteleological in that they do not directly invoke purpose or an underlying design (Mayr, 1982). Instead, such explanations comprise a variety of proximal causes that describe how an organism, including a new species, becomes perceptible. One of the more complex examples of spontaneous generation reasoning is provided by Anaximander (ca. 610-546 B.C.), an early Greek philosopher (Mayr, 1982, p. 302):

The first animals were generated in the moisture, and were enclosed within spiny barks. . . . men were formed within these [fish-like creatures] and remained within them like embryos until they had reached maturity. Then at last the creatures burst open, and out of them came men and women, who were able to fend for themselves.

Source analogies: Developmental evidence. A recent study of the emergence of beliefs about the origins of species in public elementary school children (Evans, 2000a) revealed a consistent pattern: The youngest children (5-7 years) endorsed mixed creationist and spontaneous generationist beliefs, children in the middle elementary-school years (8- to 10-year-olds) were exclusively creationist, whereas the oldest children (10.5- to 12-yearolds) were almost exclusively evolutionist with a smaller number being creationist. These children were from a university town in the mid-western United States and although their parents' beliefs were not assessed it would be reasonable to assume that the majority endorsed evolution. A second study (Evans, 2000a) was carried out in rural and suburban areas of the Midwest, where, on average, adults had fewer years of education than those in the first study. Results for the two studies were similar, except that of the oldest children and their parents in the second study about half were evolutionist and the other half were creationist; a distribution also found in surveys of the population at large (e.g., Numbers, 1992).

In the above studies it was not until early adolescence that children began to articulate evolutionary ideas, albeit of a Lamarckian variety. Moreover, in the second study, the degree to which parents endorsed evolutionary ideas 
and the degree to which children accepted the evidence for evolution, such as the fossil record, and endorsed beliefs in the inheritance of acquired characteristics (dynamic adaptation), were reliable predictors of the adoption of evolutionist explanations. Children are apparently able to suppress their essentialistic beliefs in the constancy of living kinds when confronted with convincing evidence that animals can change (Evans, 2000a). Although there appeared to be a convergence between parents' ideas about the origin of species and those of their preadolescents, parents' beliefs bore little relationship to their younger children's explanations. These findings lead one to ask what system of intuitive beliefs could account for the pattern of responses found among the younger children.

It has already been suggested that children's intuitive ontologies readily provide a source analogy for creationism in the form of a naive psychology. However, even though young children, like creation scientists, appear to adhere to the premise that species are immutable, this does not explain why they shift toward exclusive creationism rather than persisting with naturalistic spontaneous generationist explanations into the middle elementary school years. Essentialism is compatible with either explanation. Two possible reasons have been proposed, one centering on the intuitive appeal of creationist explanations, as just described, and the other on the implausibility of spontaneous generationist explanations for the origins of species (Evans, 2000a, b).

In the studies mentioned above, children's spontaneous generationist explanations drew on a variety of natural nontransformational mechanisms to describe how new species originated: "'Grew on earth from eggs ...;", "'Born in the land and crawled out;', “just appeared' (Evans, 2000a). One unusually sophisticated response was similar to that of Anaximander (see above):

... they [dinosaurs] looked like small spiky balls that eventually unfolded themselves and grew to enormous size and split themselves into plant and animal eaters-and the ones that just couldn't cope with life and they died out. (G, 10 years old)

Notably, such explanations fail to address the underlying premise of questions about species origins: how and why did the "the very first $\mathrm{X}$ " get to be there in the first place? One interpretation of the above findings is that young school-age children's naive biology is limited to proximate cause mechanisms, such as growth or birth, that could explain how an organism achieves its mature or perceptible form, but not how it comes into being (Evans, 2000a). To appreciate the final cause nature of the origins question, children must first realize that a particular kind was once nonexistent (an idea that might well be incompatible with essentialist notions of the stability of the world) - the existential question. Once this question has been broached, children are likely to wonder what purpose is served by their existence-the design stance (Dennett, 1987; Keil, 1994; Kelemen, 1999a, b). Spontaneous generation fails as a source analogy and as an explanation to the extent that it fails to address these issues. Younger children's adoption 
of spontaneous generation explanations may indicate that they have difficulty appreciating the nuances of the origins question. Creationist explanations, on the other hand, not only sanction essentialistic beliefs in the stability of species, they address the notion of original design (Evans, 2000b), and, as such, provide greater explanatory coherence (Thagard, 1989).

\section{STUDY RATIONALE: COGNITION IN CONTEXT}

These findings, although provocative, were based on children's openended responses to questions about the origins of species. They imply that the developmental sequelae emerged from interactions between changes in children's knowledge structures and the social and natural contexts in which the children were reared. However, until the study is expanded to include children from homes where creationism is fully sanctioned, as found in Christian fundamentalist communities, only limited conclusions can be drawn. Moreover, although children may not have been able to spontaneously invoke creationist or evolutionist ideas using an open-ended interview technique, they may well have endorsed such explanations had they been presented in a forced-choice or closed-ended format. The latter techniques act, in effect, as scaffolds (Rogoff, 1990), reminding children of explanations that are present publicly, which they may not have accessed without such support. Both of these drawbacks are addressed in the current study.

If ideas about the origins of species are in part derived from natural and social source analogs, as described earlier, then the extent to which children are exposed to and value those sources and associated areas of inquiry should be causally linked to children's adoption of these beliefs. To investigate these propositions in more detail, this study included some limited measures of the custom complex, that is the interconnected practices, beliefs, and values in which the child is embedded (Shweder, Goodnow, Hatano, LeVine, Markus, \& Miller, 1997). The adoption of creationist beliefs, for example, should be positively related to the degree which religious activities and interests are endorsed by the child and family, but not to interest in fossils or to unrelated interests, such as in cars or music. On the other hand, finely tuned interests in the natural world, as evidenced by children's knowledge of fossils and adaptation, and parental encouragement of such interests, should be positively related to the degree to which evolutionary ideas are endorsed.

One unexpected finding of the second of the two earlier studies (Evans, 2000a) was that about a third of the older elementary school children and adults endorsed mixed evolutionist and creationist beliefs. Some of the respondents may have embraced theistic evolution, which, as described earlier, is a coherent belief system. It is also possible that some respondents believed that humans and other animals have different origins: creationist for humans and evolutionist for other animals. However, most of these participants appeared to be struggling with what they viewed as incompatible concepts, 
suggesting that neither provided explanatory coherence (Thagard, 1989). Given that a putative source analogy for creationism is artificialism, an indicator of a coherent creationism should be the extent to which these ideas are clearly demarcated: God (but not humans) should be credited with the capacity to create natural kinds (both inanimate, e.g., rocks, and animate, e.g., animals); whereas, humans (but not God) should be credited with the capacity to create artifacts. Measures testing these propositions will also be included.

In sum, the current study draws from matched Christian fundamentalist and nonfundamentalist school communities and includes, in addition to the original open-ended origins questions, closed-ended questions targeting artifacts, inanimate and animate natural kinds, as well as some measures of the custom complex. For the purposes of this study, fundamentalist communities were defined as school communities in which biblical literalism was embraced. Analyses will be of two kinds. First, community and age group comparisons will be made to verify that these two custom complexes vary in ways that are likely to support the differential spread of creationist and evolutionist beliefs. An often unrecognized problem with this approach, however, is that each community is treated as if individual members comprised a single group with a uniform belief system (D'Andrade, 1990). As described above, even within the nonfundamentalist populations there are a range of beliefs about origins. Therefore the second set of analyses will focus on the agerelated and experiential factors that relate to individual rather than to group belief patterns.

\section{METHOD}

\section{Subjects}

Christian fundamentalist children ( $n=102$ : 48 females, 54 males) and their parents were recruited from two private Christian academies (69\%) and a Christian home-schooled group (31\%). Their homes were in 26 rural and suburban towns and cities in one Midwestern state. The nonfundamentalist children ( $n=83: 45$ females, 38 males) and their parents, matched (to the extent possible) by age and locale to the fundamentalist children, were recruited from the same or adjacent towns and cities (18 in all) using a fan-out method: $88 \%$ went to public schools, and $12 \%$ to parochial schools. Wherever possible, entire families were recruited: in the nonfundamentalist group, $95 \%$ of children had a parent who participated $(n=45)$; in the fundamentalist group, $68 \%$ of children had a parent who participated $(n=47)$. The final set of analyses focused on complete data from family groups, only.

All schools, private and public, participated in state-mandated achievement tests that included a test of scientific knowledge, which differed by grade, and included fossils, dinosaurs, and natural history. Moreover, all the schools tended to use the same science textbooks, even though the actual curriculum varied by school. However, religious studies, including a literal interpretation of the bible, were a regular part of the curriculum of the Christian fundamentalist schools only.

The children were divided into three age groups following Evans (2000a): (1) Young Group (Grades K-2) with a mean age of 6.8 years and a range of 5.3-7.9 years (nonfundamentalist, $n=25$; fundamentalist, $n=38$ ). (2) Middle Group (Grades 3-4) with a mean age of 9.1 
years and a range of 8.1-10.2 (nonfundamentalist, $n=29$ ), and a mean age of 9.0 years, 8.2-10.3 years. (fundamentalist, $n=34$ ). (3) Older Group (Grades 5-7) with a mean age of 11.5 years and a range of 10.3-12.9 years (nonfundamentalist, $n=29$ ), and a mean age of 11.9 years and a range of 10.3-13.4 years (fundamentalist, $n=30$ ). There was also an Adult Group comprising 45 nonfundamentalist and 47 fundamentalist parents (one father; the rest, mothers or female guardians).

Demographic information. The educational level of all adults in the household was supplied by the parent respondent. Using a five-point scale (1, Some High School, 2, High School; 3, Two-Year College; 4, Four-Year College; 5, Some Graduate School), the mean completed educational level of the fundamentalist mothers was $3.4(S D=0.9)$; the fathers, $3.7(S D=$ $1.0)$; and the predicted completed educational level for the child, according to the parent, 4.2 $(S D=.7)$. Levels for the nonfundamentalist families were comparable: mothers, $3.2(S D=$ $1.2)$; fathers, $3.3(S D=1.3)$; and predicted completed level for the child $4.2(S D=.8)$. There were no significant differences in parental educational levels of children from the two school communities. Seventy-two percent of the children from the fundamentalist school communities attended a Christian fundamentalist church (e.g., Church of Christ, Southern Baptist), 11\% attended a nonfundamentalist church, (e.g., Catholic, Jewish, Methodist), and $11 \%$ did not attend church regularly. In contrast, of the children attending nonfundamentalist schools, $24 \%$ attended a fundamentalist church, $42 \%$ a nonfundamentalist church, and 34\% did not attend church regularly. Churches, like the schools, were grouped as fundamentalist only if they were judged likely to embrace biblical literalism (for example, not all Southern Baptists are biblical literalists, whereas some conservative Catholics are).

\section{General Procedure}

All child interviews were conducted by the investigator and two female research assistants and lasted approximately $30 \mathrm{~min}$. Sixty percent of the interviews were conducted in the child's home, $3 \%$ in the town library, and $37 \%$ in the child's school during regular school hours. For the in-home interviews, the mother (or guardian) filled in the parent questionnaire either while the child was interviewed in a separate room or after the child interview. Following the school interviews a parent questionnaire was sent home (including a stamped, addressed envelope) with each child. The numbers of adults completing each measure varied as not all parents completed all parts of the questionnaire. The interview was developed in collaboration with members of the Christian fundamentalist communities to ensure that the wording was acceptable. To verify interview reliability and to check the accuracy of the transcripts, all interviews were audiotaped with the permission of the parent and the child. Coding of the open-ended questions was done by coders blind to both the nature of the hypotheses and the group of the subject. The specific tasks and coding criteria for both children and parents will be described in four sections: (1) Open-ended origins task; (2) Closed-ended origins task; (3) Is the human a special case? (4) Natural-history knowledge, interests, and activities.

Task order. After the child was asked some initial demographic questions, the first task focused on the child's interests. This was followed by the open-ended origins task, the closedended origins task, and the natural-history questions. For the parents the task order was similar, except that following the demographic questions parents were given a closed-ended task that probed whether their origins explanations differed depending on the target (human versus dinosaur) and the age of the child. In place of the natural-history questions given to the child, parents were asked what activities and interests they encouraged in their children, as the focus of the interviews was on the child's knowledge and interests (not the parent's).

\section{Origins Explanations: Open-Ended}

The children's task was introduced with the following statement that was worded to draw their attention to the idea that a species may not have existed in the past (Evans, 2000a). "I 
am going to ask you some questions. There are no right or wrong answers to these questions, just different kinds of ideas. Think about how the very first things got here on earth. A long, long time ago there were no things on earth. Then there were the very first things ever. Now, think about the Target Item [Target Item description]. How do you think the very first Target Item got here on earth?' (if no answer was elicited, there were two probes). The three target items were the sun bear [a kind of bear from Asia], the tuatara [a kind of lizard from New Zealand], and the human. All items were presented verbally only. The human was always last, with the order of the other two targets alternated between subjects. The tuatara and sun bear were considered to be unfamiliar and unlikely to elicit well-rehearsed knowledge.

The parent questionnaire included the following statement: "Imagine you were teaching a 10- to 12-year old child you know, and he or she had asked you the following questions. Please briefly write down your answers. The questions were 'How did the very first Target Item [Target Item description] get here on earth?" The target items, which were presented in a fixed order, were, tuatara, sun bear, and human. The age of the target child was based on results from earlier studies (Evans, 2000a), in which it appeared that by 10-12 years of age children had converged on the beliefs of the adult population.

Coding criteria. Responses to both the parent and the child origins questions were coded into four explanation patterns (as well as Don't Know and Other), as in Evans (2000a). Spontaneous Generation, responses indicating a natural but non-transformational origin for species (e.g., "'grew from the earth," "born in the earth," "'appeared"'); Creation, responses indicating that God, a human, or another creature, created, planned, or put a species on earth; Evolution, responses indicating the transformation from one distinct animal kind into another (indicated by different species names, e.g., gorilla to a person or fish to a dinosaur); Hybridization, responses indicating that new species arose because of the interbreeding of two different species.

All responses were coded by two people. Interrater agreement for the assignment to explanation pattern for the origins questions for the first 100 subjects (approximately half fundamentalist and half nonfundamentalist) was as follows: tuatara origins (86\%); sun bear origins (94\%); human origins (97\%). All disagreements were subsequently resolved by discussion.

\section{Origins Explanation: Closed-Ended}

The intent of this task was to investigate children's origins explanations with a forcedchoice, recognition technique and to investigate the extent to which subjects' explanations were similar across diverse entities, representing different domains (animate, artifacts, inanimate). For all the explanations, prototypic exemplars were selected from children's open-ended responses given in earlier studies (e.g., Evans, 2000a). Owing to the diversity of children's spontaneous generationist explanations, two exemplars were chosen, both of which could be applied to any type of entity (they did not reference a biological process such as growth or birth); the selected evolutionist explanation overtly repudiated the essentialist notion of immutability. To represent the putative source analogy for creationism (God-made), an artificialist (human-made) explanation was also included. Pilot testing indicated that among adults the creationist exemplar was likely to elicit a positive response from biblical literalists but not from theistic evolutionists, who did not find this form of creationism acceptable.

Task. The children viewed seven pictures, randomly selected one at a time from a bag, consisting of three animate entities (sun bear, tuatara, human), two inanimate entities (rock, crystal) and two simple artifacts (toy chair, doll). For each pictured Target Item, children were asked to what extent they agreed or disagreed with five statements (also randomly ordered) about the origins of the entity. Children used an Agree-Disagree card with a four-point scale to indicate how much they agreed with each statement. On the card there were four expressive faces indicating either disagreement (1, a lot; 2, a little) or agreement (3, a little; 4, a lot). Children were first trained to use the card, and no child had problems with its use. If any question elicited a "don't know" response the question was repeated twice; if the child per- 
sisted with a "don't know" response, a neutral 2.5 was assigned for that explanation and target (this happened rarely; less than $0.5 \%$ cases). The origins question was always: "How did the very first Target Item get here on earth?', The origins explanations consisted of the following: Creationist ("God made it and put it on earth"), Artificialist ("A person made it and put it on earth"), Evolutionist ("It changed from a different kind of animal that used to live on earth'), Two spontaneous-generationist explanations ("It just appeared; It came out of the ground"').

Adults were given the same task in a questionnaire format. For the adults the entities were presented in a fixed order (doll, tuatara, rock, crystal, sun bear, chair, human), and for each entity the origins explanations were in a different fixed order. Adults also used the same fourpoint, agree-disagree scale to indicate the degree to which they would endorse the explanation. Both adults and children could (and did) designate intermediate points on the scale and their responses were given proportional values (e.g., 3.5).

\section{Is the Human a Special Case?}

This measure was designed to elicit possible changes in the way parents explained their beliefs about human origins versus dinosaur origins to children of different ages. If the source analogy for creationism is a folk psychology, then parents might apply creationist explanations more often to the human than to other animals; moreover, even nonfundamentalist parents might be more likely to explain species origins in creationist terms to younger children.

In the questionnaire parents were told, "what follows are some explanations about origins that adults might give to children of different ages. As they are examples of children's answers (from an earlier study), we would not expect adults to give exactly the same explanations. We want to know if you would give similar explanations to your own children.' Parents used a five point scale anchored at 1, I would never-; 3, I might give-; and 5, I'm very likely(to) give a similar explanation. Parents rated the likelihood of giving these explanations to children in each of the following age groups: 3-5 years, 6-9 years, 10-12 years (preschool, early-mid elementary, late elementary). Twelve explanations for dinosaur origins were followed by twelve explanations for human origins; they comprised the following groups, with no two explanations from the same group appearing next to each other: (1) Spontaneous generationist-four items (e.g., came alive suddenly; they were just born in a cave; could have just appeared), (2) Creationist-four items (e.g., God made the dinosaurs; God made the humans and put them on earth), (3) Evolutionist-four items (e.g., a long time ago dinosaurs began as sea-animals; humans evolved from other creatures such as the ape).

\section{Natural-History Knowledge, Interests, and Activities}

Children (but not parents) were given 12 randomly ordered statements on natural history, which were based on typical misconceptions exhibited by children in earlier studies (Evans, 2000a): 6 were true and 6 were false. Responses to 9 statements on fossils and deep time were grouped into a measure called Fossil Expertise. The 3 remaining statements probed for children's agreement with the idea that animals acquire new features in response to changed environmental conditions, called Dynamic Adaptation (see Appendix). Children used the previously described Agree-Disagree card (with the same four-point scale) to indicate how much they disagreed or agreed with each statement.

Children also participated in four tasks in which they were shown five randomly ordered pictures of specific interests and activities common to children in this age range. They rank ordered the pictures from those they liked the most (to read about, to collect, to visit, etc.), to those they liked the least; each interest was then assigned a number from 1 (the least) to 5 (the most), for each task (several were filler items). In addition, children used a five-point scale (1, Never; 3 , Once or more a year; 5 , Once or more a week) to indicate how often they engaged in five different activities. Conceptually related items from these tasks were grouped 
(3-5 items per group) into four measures of interest (Range, 1-5): (1) Religious (e.g., like to read bible stories; like to go to church; frequency of church attendance); (2) Fossil (e.g., like to read about fossils and rocks; like to collect fossils and rocks); (3) Dinosaur (e.g., like to collect model dinosaurs; like to go to dinosaur museums); (4) General (e.g., Like to read make-believe stories; like to collect stamps; like to go swimming; like to go to movies).

Parents rated the importance of 25 potential child interests and activities (including three practice items) using a five-point scale anchored at 1, Not at all Important; 3, Important; and 5, Very Important-for their "child to do or to have." The activities were presented in a fixed order (with the constraint that no two activities from the same group appeared successively) and comprised the following groups (5-6 items per group): (1) Musical (e.g., to learn how to sing; to play a musical instrument), (2) Religious (e.g., to learn about Jesus and other religious figures; to go to a church, synagogue, or other place of worship regularly), (3) Fossil and Dinosaur (e.g., to go to rock and fossil museums; to have books on dinosaurs), (4) Nature (e.g., to have their own plants; to go on nature walks).

\section{RESULTS AND DISCUSSION}

\section{Part One: Community Comparisons}

\section{Origins Explanations: Open-Ended}

The main question addressed in this analysis is whether previous agerelated patterns of explanation for the origins of species found in nonfundamentalist school communities ${ }^{2}$ (Evans, 2000a), are also found in the fundamentalist school community. The findings indicate that creationist responses predominate in each age group in the fundamentalist community, while naturalistic responses (evolution and spontaneous generation) are rarely endorsed. This is unlike the pattern for the nonfundamentalist population where the dominant response depended on the age of the participants.

The basic measure, called frequency of explanation, was computed by recording the number of times participants invoked each of the explanations of interest (evolution, creation, spontaneous generation) across the three animate exemplars (human, sun bear, tuatara); the hybridization explanation was invoked too rarely to be included in the analysis. The possible range of scores for each explanation was 0-3. Mean frequency scores (and standard errors), by age group, in the nonfundamentalist and fundamentalist communities can be seen in Fig. 1. The origins-explanation frequency scores were analyzed in a 2 (Community: Fundamentalist, NonFundamentalist) $\times 4$ (Age group: Young, Middle, Older, Adult) $\times 3$ (Explanation: Evolution, Creation, Spontaneous Generation) mixed-design analysis of variance (ANOVA), ${ }^{2}$ with origins-explanation as the repeated measure. There was a main effect for origins-explanation, $F(2,510)=230.8, p<.0001$, and three significant interactions: origins-explanation $\times$ age group, $F(6,510)=10.7, p<.0001$; origins-explanations $\times$ community, $F(2,510)=50.4, p<.0001$; and

${ }^{2}$ Further details of results on this measure (frequency of explanation) with the nonfundamentalist group only can be found in Evans (2000a). 


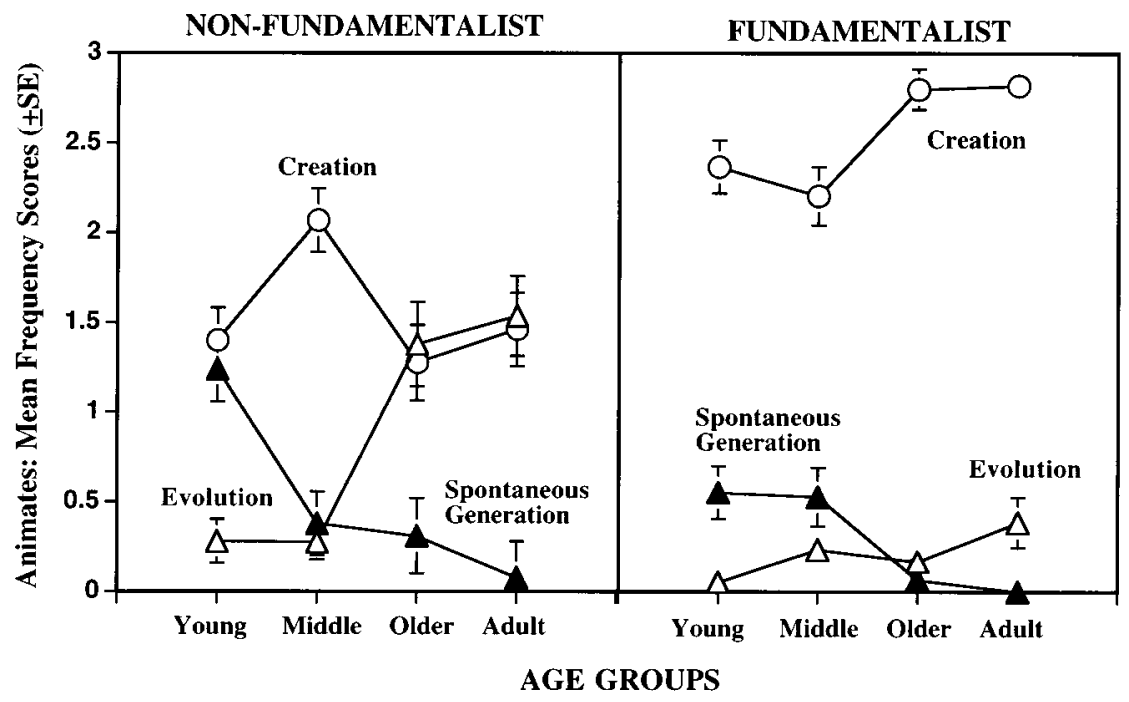

FIG. 1. Mean frequency scores for three explanations for the origins of species in fundamentalist and nonfundamentalist elementary school communities, by age group.

origins-explanations $\times$ age group $\times$ community, $F(6,510)=7.5, p<.0001$. (A separate repeated measure ANOVA, without the adult group, included gender and found no significant main effects or interactions with gender.) To clarify the nature of the interactions post hoc Scheffé comparisons were carried out separately within each school-community by age group, and then certain hypothesis-related comparisons were made between communities within each age group to verify the reported pattern. The overall focus was on the pattern of explanation preferences characterizing a particular age group (see Fig. 1).

Nonfundamentalist school community. Among the young age group, creation and spontaneous generation were favored over evolution ( $p$ 's $<.007$ ), with no significant difference between creation and spontaneous generation. For the middle age group, in contrast, creation was favored over both evolution and spontaneous generation ( $p$ 's $<.0001$ ), with no significant difference between the latter pair of explanations. In both the older age group and the adults there were no significant differences between creation and evolution and both were favored over spontaneous generation $(~ p$ 's $<.02)$.

Fundamentalist school community. In all age groups, including the adults, creation was favored over both evolution and spontaneous generation ( $p$ 's $<$ .0001). Of the two least-preferred explanations, the young children tended to invoke spontaneous generation more often than evolution $(p<.07)$, with no significant difference in the middle and older age groups; among the 
adults, however, evolution was favored over spontaneous generation as a less-preferred explanation $(p<.05)$.

Summary. Comparisons of the results from two school communities (see Fig. 1) suggest that the two natural explanations (evolution and spontaneous generation) were almost completely suppressed in the fundamentalist community relative to the nonfundamentalist community. Thus, creationist explanations predominated in every age group among the fundamentalists, but in the nonfundamentalist school community it was only in the middle age group that creation was the single most favored explanation. Confirming the latter pattern, with the exception of the middle age group, significant differences were found between the two communities in each age group for the frequency of creationist explanation $(p$ 's $<.0002)$.

\section{Origins Explanations: Closed-Ended}

The next set of analyses focused on whether the same patterns of explanation would be found with the use of a forced choice rather than an openended method. In addition, adults and children were asked to what extent they agreed that natural (evolution, spontaneous generation) or intentional (creationist, artificialist) origins explanations could be applied not only to animate natural kinds, but also to artifacts and to inanimate natural kinds. The use of closed-ended or forced-choice questions gave participants the opportunity to explicitly consider all explanations, making it possible for explanations that are not easily invoked in an open-ended recall procedure to be endorsed when using a closed-ended recognition procedure.

As can be seen in Fig. 2, although the same overall pattern is apparent with the use of the forced choice procedure for the animate entities, there is an increase in creationist responses, especially among younger nonfundamentalist children. Additionally, there is an effect of domain with spontaneous generation favored for inanimate entities and artificialism for artifacts.

A measure termed origins-explanation agreement was constructed for each origins explanation; this was the mean level of agreement (scale, 1-4) with each origins explanation for each of the three domains: animates, artifacts, and inanimates. In order to limit the number of analyses, only one of the two spontaneous generation exemplars, "It came out of the ground," was used to represent that explanation (the results for both exemplars were similar for the animates). For each domain the origins-agreement scores were analyzed in a 2 (Community: Fundamentalist, Nonfundamentalist) $\times 4$ (Age group: Young, Middle, Older, Adult) $\times 4$ (Explanation: Creation, Evolution, Spontaneous-Generation, Artificialist) mixed-design ANOVA, with explanation as the repeated measure. Where there were significant interactions, post hoc Scheffé comparisons focused on the pattern of explanation preferences characterizing a particular age group; differences between explanations that were rejected by the participant (disagree on the agree-disagree scale) will 


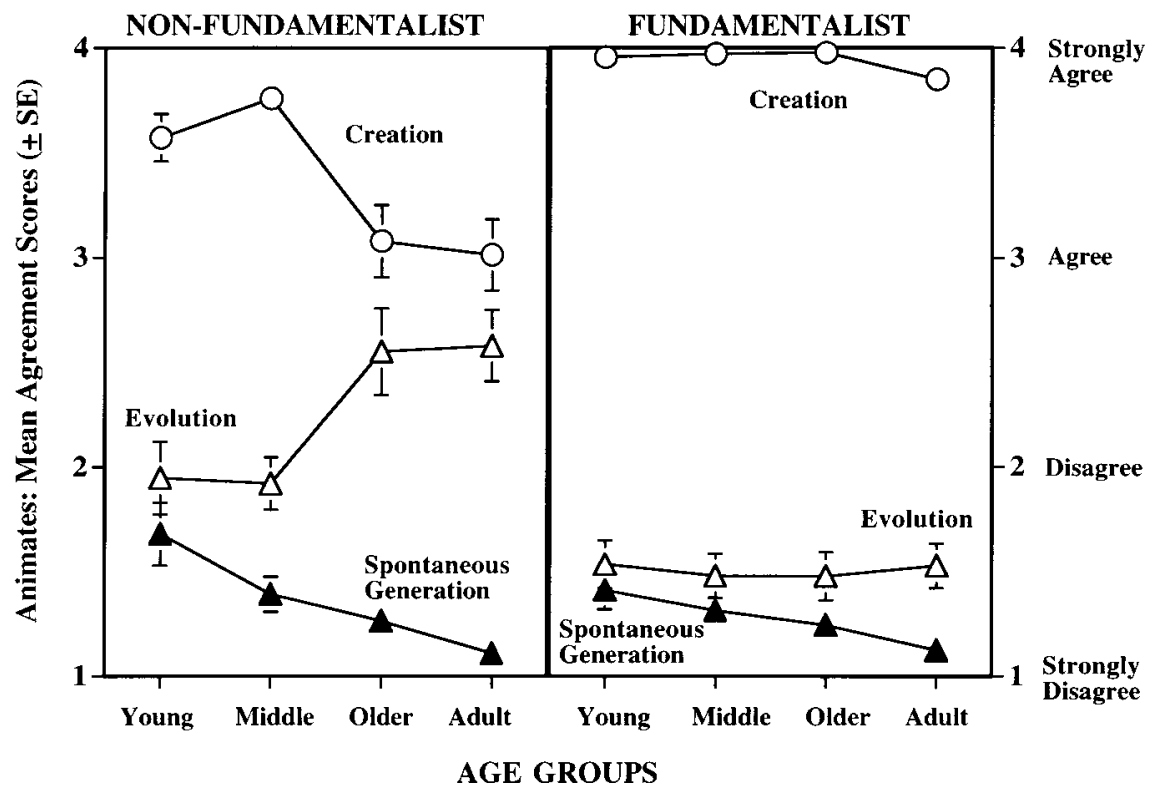

FIG. 2. Animate origins: Mean agreement scores for three explanations, in fundamentalist and nonfundamentalist elementary school communities, by age group.

not be reported in any detail, but they do provide evidence that children were evaluating the explanations appropriately. As before, selected further comparisons were made between communities within each age group to verify the reported pattern.

Animate origins. There were significant main effects for community, $F(1$, $268)=4.8, p<.03$, age group, $F(3,268)=10.6, p<.0001$; and explanation, $F(3,804)=765.0, p<.0001$; means and standard errors can be seen in Fig. 2 (artificialism was rejected: means $<2$ ). Additionally, there were significant interactions: explanation $\times$ age group, $F(9,804)=8.3, p<$ .0001 ; explanation $\times$ community, $F(3,804)=33.93, p<.0002$; and explanation $\times$ age group $\times$ community, $F(9,804)=3.7, p<.0003$. In the young and middle nonfundamentalist age groups, creation was favored over all other explanations $(p$ 's $<.0001)$. In the older age group and the adults there was no significant difference between creation and evolution and both were favored over both spontaneous generation and artificialism ( $p$ 's $<.0001)$. In all age groups in the fundamentalist school community, creation was the most strongly endorsed of all explanations ( $p$ 's $<.0001)$. Between-community comparisons showed significant differences in each age group for creation (fundamentalists higher, $p$ 's $<.0003$ ) and evolution (nonfundamentalists higher: young-group, $p<.05$; the other age groups, $p$ 's $<.009$ ). 


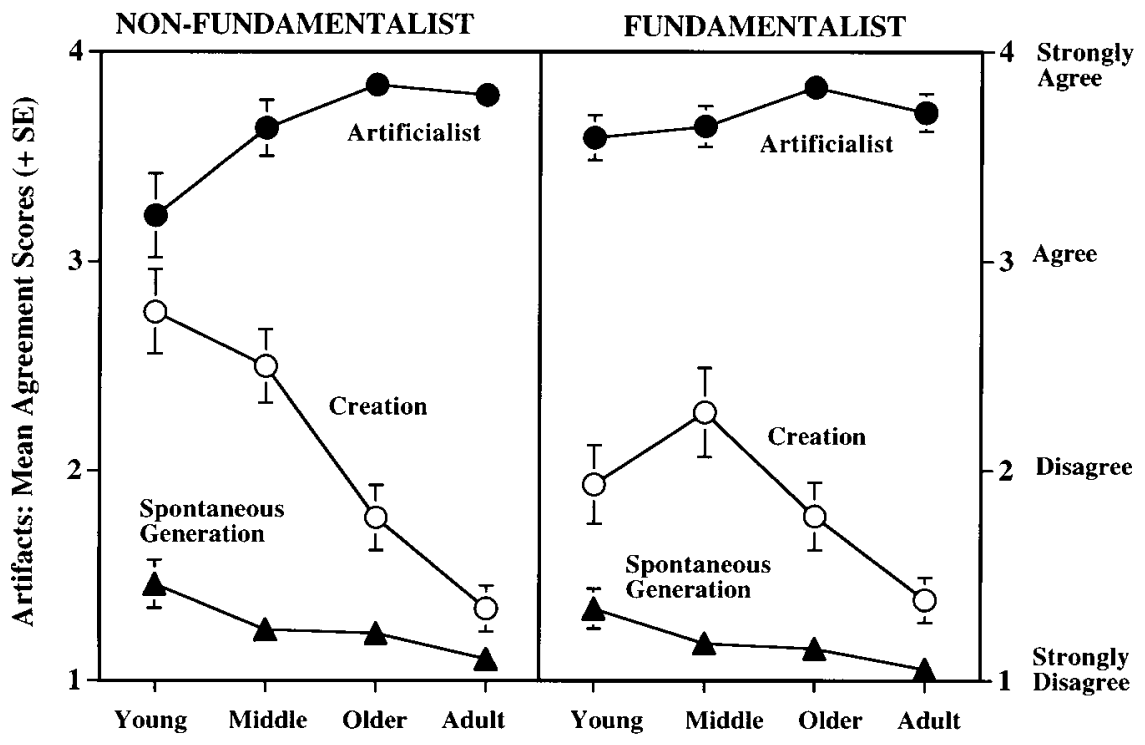

AGE GROUPS

FIG. 3. Artifact origins: Mean agreement scores for three explanations, in fundamentalist and nonfundamentalist school elementary school communities, by age group.

Artifact origins. There were significant main effects for community, $F(1$, $268)=4.3, p<.04$, age group, $F(3,268)=20.0, p<.0001$, and explanation, $F(3,804)=861.8, p<.0001$; means and standard errors can be seen in Fig. 3 (spontaneous generation was rejected: means $<2$ ). Additionally, there were significant interactions: explanation $\times$ age group, $F(9,804)=$ $13.8, p<.0001$; explanation $\times$ community, $F(3,804)=2.8, p<.04$, and explanation $\times$ age group $\times$ community, $F(9,804)=2.5, p<.007$. In both communities artificialism was favored over all other explanations $(p$ 's $<$ .0001), with the exception of the young nonfundamentalist children, for whom creationist and artificialist origins were preferred equally. Betweencommunity comparisons within each age group for artificialism and creation showed differences in the young age group only, with creation more likely to be endorsed in the nonfundamentalist community $(p<.006)$. (This interesting result will be investigated in more detail later.)

Inanimate origins. There were significant main effects for age group, $F$ (3, $268)=15.9, p<.0001$, and explanation, $F(3,804)=362.0, p<.0001$; means and standard errors can be seen in Fig. 4 (evolution was rejected: means $<2$ ). Additionally, there were significant interactions: explanation $\times$ age group, $F(9,804)=3.3, p<.0007$; explanation $\times$ community, $F(3$, $804)=39.0, p<.0001 ;$ and explanation $\times$ age group $\times$ community, $F(9$, $804)=2.3, p<.02$. In the fundamentalist community, creation was the 


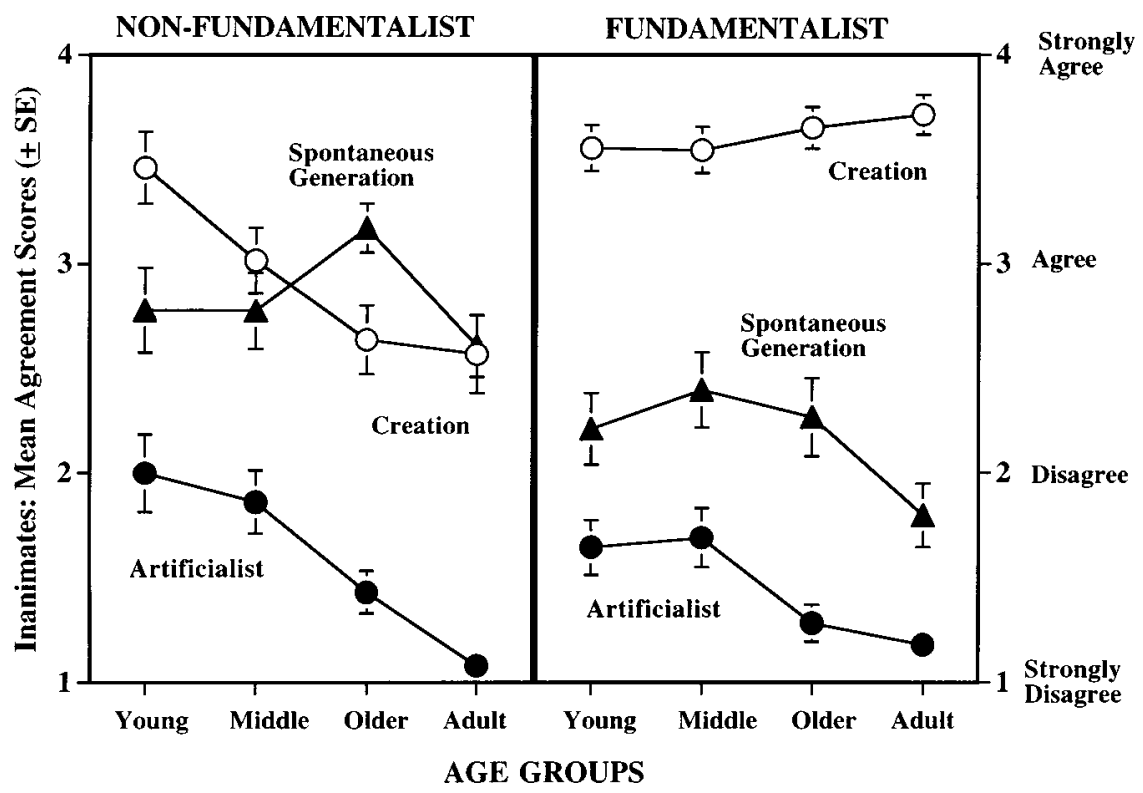

FIG. 4. Inanimate origins: Mean agreement scores for three explanations, in fundamentalist and nonfundamentalist elementary school communities, by age group.

explanation of choice for all age groups ( $p$ 's $<.0001)$, though spontaneous generation was significantly preferred over artificialism and evolution ( $p$ 's $<$ .02). Among the nonfundamentalists, spontaneous generation and creation were both strongly endorsed by all age groups. For the older age group, spontaneous generation was favored over creation $(p<.05)$, whereas for all the other age groups both explanations were equally endorsed. Betweencommunity comparisons within age groups reveal that with the exception of the young age group, where spontaneous generation and creation were both endorsed equally, creation was more likely to be endorsed in the fundamentalist than in the nonfundamentalist community ( $p$ 's $<.007)$. On the other hand, with the exception of the middle age group, where they were endorsed equally, spontaneous generation was more likely to be endorsed in the nonfundamentalist community ( $p$ 's $<.04$ ).

Summary. The overall developmental pattern for animate entities with the forced-choice questions was similar to that found with the open-ended questions, with the interesting exception of the younger nonfundamentalist children: they were more likely to endorse creation and less likely to endorse spontaneous generation with the forced-choice paradigm. Notably, however, the younger children still did not endorse evolution. The lack of endorsement for spontaneous generation could result from several factors, which will be discussed in some detail later. One possibility, however, is that the exemplar 
"came out of the ground" was too specific, although it was a frequent response to the open-ended questions. However, the second spontaneous generation exemplar "it just appeared" potentially had a broader appeal, yet the pattern of responses for the two exemplars was very similar, especially for the animate entities. Of course, it is possible that the spontaneous generationist exemplar (came out of the ground) would have been deemed plausible as an explanation for animate origins by more children if it had been linked to a biological cause (growth, birth), which was done by some children in the open-ended measure.

An interaction between domain and explanation was also found. For artifacts, members of all communities endorsed artificialism, again with the exception of the young nonfundamentalists who appeared to conflate artificialism and creationism. On the other hand, spontaneous generation was more likely to be endorsed for inanimate natural entities than for animates or artifacts, by all age groups in both communities.

\section{Is the Human a Special Case?}

Initial analyses focus on whether the overall pattern of explanations endorsed by parents differed depending on the type of exemplar (human or dinosaur) and the type of school community (fundamentalist and nonfundamentalist). It was found that the type of exemplar does have an effect on parental responses especially in the nonfundamentalist community.

Parental endorsement of each explanation (range 1-5: evolution, creation, and spontaneous generation) was analyzed in a 2 (Community: Fundamentalist, Nonfundamentalist) $\times 2$ (Exemplar: Human, Dinosaur) mixed-design ANOVA, with exemplar as the repeated measure. In this analysis no distinction was made between age groups. As expected, nonfundamentalist parents were much more likely to endorse evolution overall, $F(1,77)=35.4, p<$ .0001 , but parents from both communities were more likely to apply evolution to the dinosaur (means: 1.6 and 2.9) than to the human (means: 1.3 and $2.2), F(1,77)=39.8, p<.0001$. On the other hand, fundamentalist parents were more likely to endorse creationism overall $F(1,77)=15.4, p<.0003$, but both groups were more likely to apply creation to the human (means: 3.6 and 4.6) than to the dinosaur (means: 2.9 and 3.6), $F(1,77)=94.5$, $p<.0001$. Although neither community was likely to endorse spontaneous generation explanations (means: 1.1 to 1.4 ), when they did, they were more likely to apply them to the dinosaur than to the human $F(1,77)=19.5, p<$ .0001 .

The next analyses are broken down by the targeted age group: preschool, early-mid elementary, late elementary. Members of the fundamentalist community consistently endorsed creationism, and parents, in general, rarely endorsed spontaneous generation; therefore these analyses focused on nonfundamentalist parents and whether they felt they would tailor their creationist or evolutionist explanations to the age of the child. Nonfundamentalist par- 
ents were significantly more likely to explain human and dinosaur origins in evolutionary terms to both age groups of elementary school children, than to their preschool children ( $F$ 's 16.0 to 19.0 ; $p$ 's $<.0001$ ). Moreover, nonfundamentalist parents were more likely to give creationist explanations for dinosaur origins to their preschoolers, than to the two elementary school groups $(F=3.1 ; p<.05)$; they did not discriminate between age groups, however, when giving creationist explanations for human origins.

To confirm this indication that the human is treated as a special case, a secondary analysis of answers to the earlier closed-ended origins questions was conducted to see if this result would hold true across explanations that were identical for human and nonhuman targets. For the closed-ended origins questions reported earlier, the human and the two nonhuman species (tuatara, sun bear) were separated into two measures (human versus nonhuman) and compared using one-tailed, paired $t$-tests. Overall, evolution, $t(275)=5.2$; $p<.0001$, was more likely to be applied to the nonhuman species, and creation to the human, $t(275)=2.0 ; p<.03$. When the results were broken down by community and age group, a clearer picture emerged for creation. The preferential use of creation for the human was evident only in the middle age groups from both communities and in adult members of the nonfundamentalist community ( $t$ 's 2.2 to 3.5 ; $p$ 's $<.02$ to $<.0007$ ). These results provide corroborative evidence for the previous findings.

Summary. A possible cause of the age-related sequence of beliefs exhibited by nonfundamentalist children is that parents change their explanations depending on the age of the child, though it would be difficult to determine the causal direction of the effect. However, given the inconsistency of the pattern, direct parental input seems unlikely to have contributed much to the developmental sequelae. Both measures described above indicate that humans are treated as a special case, especially in nonfundamentalist settings, and are more likely than nonhuman species to elicit creationist origins. Moreover, these results demonstrate that parents, particularly nonfundamentalist parents, are likely to manifest mixed beliefs: evolution applied to nonhuman species and creation to the human.

\section{Natural-History Knowledge, Interests, and Activities}

The next analyses targeted some limited measures of the custom complex in fundamentalist and nonfundamentalist homes and schools, to evaluate whether they differed in ways consistent with the differences in beliefs between the two communities. As can be seen in Table 1, this effect is apparent in the expected areas of expertise and interest.

Mean scores for the measures of children's natural-history knowledge and interests, and parents' encouragement of child interests, by school community, are presented in Table 1. (The higher the score the more expert or interested they were, depending on the measure, and the more likely they 


\section{TABLE 1}

Natural-History Knowledge and Interests of Elementary-School Children in Fundamentalist and Nonfundamentalist School Communities: Means (Standard Deviations)

\begin{tabular}{lccc}
\hline \multicolumn{1}{c}{ Measure (Range) } & Nonfundamentalist & Fundamentalist & $F$ value \\
\hline Child natural-history knowledge & & & \\
$\quad$ Fossil expertise (1-4) & $2.9(.4)$ & $2.7(.4)$ & $12.5 * * *$ \\
$\quad$ Dynamic adaptation (1-4) & $2.0(.8)$ & $1.7(.8)$ & $7.4^{* *}$ \\
Child interests & & & \\
Religious (1-5) & $2.8(.9)$ & $3.5(.9)$ & $23.9 * * *$ \\
Fossil (1-5) & $2.9(.9)$ & $2.6(.9)$ & $4.9 *$ \\
$\quad$ Dinosaur (1-5) & $2.7(.9)$ & $2.8(1.0)$ & 0.2 \\
General (1-5) & $3.4(.9)$ & $3.3(.7)$ & 1.6 \\
Parent encouragement of child interests & & & \\
Religious (1-5) & $3.5(1.0)$ & $4.6(.5)$ & $41.6 * * *$ \\
Dinosaurs/fossils (1-5) & $3.6(.8)$ & $3.1(.8)$ & $8.7 * *$ \\
Nature (1-5) & $3.9(.6)$ & $3.6(.7)$ & $6.2 *$ \\
Music (1-5) & $3.4(.8)$ & $3.2(.8)$ & 2.7 \\
\hline
\end{tabular}

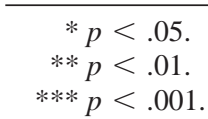

were to endorse the belief in the inheritance of acquired features). One-way ANOVAs with Community (2) conducted on each of the measures ( $F$ values reported in Table 1) showed that members of these two school communities differed on those interests putatively related to their belief systems (religion, fossils), but not on more neutral interests (general interests, music). Interestingly, although nonfundamentalist children were more knowledgeable about fossils, they were more likely than fundamentalist children to accept the false notion that acquired features could be inherited (dynamic adaptation). Children from both communities were interested in dinosaurs, although they differed in their interest in fossils. This finding fits in with other findings (Evans, 2000a) that children's ability to sort and describe dinosaurs does not necessarily entail the knowledge that dinosaurs are an important part of the fossil record.

Analyses of the effects for gender on child interests indicate main effects only: In both communities, females preferred religious activities $(F=10.4$; $p<.002)$ and general interests $(F=76.3 ; p<.0001)$, and males, fossils $(F=16.3 ; p<.0001)$ and dinosaurs $(F=57.5 ; p<.0001)$. There were no effects for gender, however, on either measure of child natural-history knowledge.

Summary. Overall, children and parents from fundamentalist communities were more likely to endorse religious interests, whereas those from nonfundamentalist communities were more likely to endorse interests in nature and 
fossils. Interests in music and more general interests in sports, cars, dolls, etc., were endorsed equally by both communities.

\section{Part Two: Individual Differences}

\section{Typology of Belief: Implications for Explanatory Coherence}

The above results demonstrate that participants often manifested mixed beliefs with evolution applied preferentially to nonhuman species and creation to the human. As group results obscure individual differences it is not clear whether of the adult nonfundamentalists half were evolutionist and half creationist or whether most endorsed mixed creationist and evolutionist beliefs (see Fig. 1). To examine such individual differences in more detail, composite measures of the consistency of beliefs were derived from the origins questions described earlier and used to create a typology of beliefs for each community; the coherence of these explanatory systems was then explored by comparing these typologies.

Beliefs that appear to contradict one another are defined as incoherent (see Thagard, 1989); it would follow that they are unlikely to exist as related concepts within a coherent explanatory framework. The belief that God created each living kind as an exclusive and immutable entity and the belief that each living kind evolved, for example, are mutually exclusive. However, as can be seen in Tables 2-5, the beliefs of many of the participants, particularly those in the nonfundamentalist community, appear to be incoherent in that they endorse both creationist and evolutionist explanations.

\section{TABLE 2}

Animate Origins: A Typology of the Frequency of Evolutionist and Creationist Beliefs among Elementary School Children (Young, 5-7 Years; Middle, 8-10 Years; Older, 11-13 Years) and Adults from Nonfundamentalist and Fundamentalist School Communities (Percentage of Group)

Age group

\begin{tabular}{lllll}
\cline { 2 - 3 } Typology & Young & Middle & Older
\end{tabular}

Nonfundamentalist school community

(1) Evolution/No Creation

(2) Evolution and Creation

(3) Creation/No Evolution

(4) Neither

Fundamentalist school community

(1) Evolution/No Creation

(2) Evolution and Creation

(3) Creation/No Evolution

(4) Neither

$\begin{array}{rrrr}0 & 3 & 34 & 26 \\ 22 & 21 & 31 & 33 \\ 56 & 76 & 35 & 36 \\ 22 & 0 & 0 & 5 \\ & & & \\ 0 & 3 & 3 & 3 \\ 5 & 15 & 10 & 18 \\ 92 & 82 & 87 & 79 \\ 3 & 0 & 0 & 0\end{array}$

Note. This typology was constructed from the open-ended frequency measure for the animates: Creation frequency-Evolution frequency (see Fig. 1). 


\section{TABLE 3}

Animate Origins: A Typology of Evolutionist and Creationist Beliefs (Agreement) among Elementary School Children (Young, 5-7 Years; Middle, 8-10 Years; Older, 11-13 Years) and Adults from Nonfundamentalist and Fundamentalist School Communities (Percentage of Group)

Age group

Typology

\begin{tabular}{lll}
\multicolumn{4}{c}{ Age group } \\
\hline Young $\quad$ Middle $\quad$ Older $\quad$ Adult
\end{tabular}

Nonfundamentalist school community

(1) Evolution/No creation

\begin{tabular}{rrrr}
0 & 0 & 21 & 27 \\
20 & 17 & 28 & 25 \\
76 & 79 & 48 & 48 \\
4 & 4 & 3 & 0 \\
& & & \\
0 & 0 & 0 & 2 \\
8 & 9 & 7 & 8 \\
92 & 91 & 93 & 90 \\
0 & 0 & 0 & 0 \\
\hline
\end{tabular}

(2) Evolution and creation

(3) Creation/No evolution

(4) Neither

Fundamentalist school community

(1) Evolution/No creation

(2) Evolution and creation

(3) Creation/No evolution

(4) Neither

Note. This typology was constructed from the closed-ended origins agreement measure for the animates: Creation agreement-Evolution agreement (see Fig. 2).

Animates. Two composite measures of belief consistency (evolution-tocreation) were constructed by combining the evolution and creation responses for the animates. The first measure was based on the frequency scale (0-3) from the open-ended questions (see Table 2) and the second measure on the agreement scale (1-4) from the closed-ended questions (see Table

\section{TABLE 4}

Artifact Origins: A Typology of the Artificialist and Creationist Beliefs among Elementary School Children (Young, 5-7 Years; Middle, 8-10 Years; Older, 11-13 Years) and Adults from Nonfundamentalist and Fundamentalist School Communities (Percentage of Group)

\begin{tabular}{lllll} 
& \multicolumn{4}{c}{ Age group } \\
\cline { 2 - 5 } Typology & Young & Middle & Older & Adult
\end{tabular}

Nonfundamentalist school community

(1) Artificialism/No creation

(2) Artificialism and creation

(3) Creation/No Artificialism

(4) Neither

Fundamentalist school community

(1) Artificialism/No creation

(2) Artificialism and creation

(3) Creation/No Artificialism

(4) Neither

$\begin{array}{rrrr}20 & 45 & 72 & 89 \\ 56 & 41 & 25 & 7 \\ 16 & 14 & 0 & 2 \\ 8 & 0 & 3 & 2 \\ 61 & 47 & 73 & 85 \\ 23 & 44 & 27 & 9 \\ 3 & 3 & 0 & 4 \\ 13 & 6 & 0 & 2\end{array}$

Note. This typology was constructed from the closed-ended origins agreement measure for the artifacts: Creation agreement-Artificialism (human-made) agreement (see Fig. 3). 


\section{TABLE 5}

Inanimate Origins: A Typology of Spontaneous Generationist and Creationist Beliefs among Elementary School Children (Young, 5-7 Years; Middle, 8-10 Years; Older, 11-13 Years) and Adults from Nonfundamentalist and Fundamentalist School Communities (Percentage of Group)

Age group

Typology

Young Middle Older

Adult

Nonfundamentalist school community

(1) Spontaneous generation/No creation

(2) Spontaneous generation and creation

(3) Creation/No spontaneous generation

(4) Neither

Fundamentalist school community

(1) Spontaneous generation/No creation

(2) Spontaneous generation and creation

(3) Creation/No spontaneous generation

(4) Neither

$\begin{array}{rrrr}8 & 21 & 48 & 30 \\ 52 & 34 & 28 & 27 \\ 28 & 28 & 17 & 23 \\ 12 & 17 & 7 & 20 \\ & & & \\ 5 & 6 & 7 & 4 \\ 29 & 39 & 30 & 21 \\ 53 & 44 & 60 & 66 \\ 13 & 11 & 3 & 9\end{array}$

Note. This typology was constructed from the closed-ended origins agreement measure for the inanimates: Creation agreement-Spontaneous Generation agreement (see Fig. 4).

3). In both cases, the evolution responses (Evolution Frequency or Evolution Agreement) were subtracted from the creation responses (Creation Frequency or Creation Agreement). In the resulting composite measures of belief consistency (evolutionist-to-creationist; range, -3 to +3 ), higher positive scores indicate more consistent creationism, lower negative scores more consistent evolutionism, with intermediate scores indicating some type of mixed beliefs. Based on these consistency measures (and the original data) typologies were then created in which participants were divided into four groups: pure evolution (no creation), mixed evolution and creation, pure creation (no evolution), and neither evolution nor creation. As the agreement scale spanned a range from (1) strongly disagree to (4) strongly agree, the following criteria were used to construct the 'agreement' typology: (1) Evolution $(>2.5)$, No Creation $(\leq 2.5)$; (2) Evolution and Creation $(\geq 2.5$ for both); (3) Creation $(>2.5)$, No Evolution $(\leq 2.5)$. If participants did not agree with either explanation ( $\leq 2.5$ for both explanations, where $2.5=$ neither agree nor disagree) they were placed in a "neither" category. The percentage of participants falling into each of these groups in the two communities is presented by age group in Table 2, for the frequency measure, and in Table 3, for the agreement measure. As spontaneous generation was rarely endorsed in the closed-ended animate measures it was not included in these analyses (but see Evans, 2000a).

In the open-ended frequency measure participants had to construct rather than recognize explanations, which was presumably a more difficult task than the closed-ended agreement measure where "reminders", were given. 
The typologies presented in Tables 2 and 3 demonstrate that in both school communities more participants exhibited mixed beliefs with the open-ended frequency measure. With the closed-ended agreement measure, pure creationism was endorsed more strongly by all groups of participants. Moreover, young nonfundamentalist children readily endorsed creationist (but not evolutionist) explanations with the agreement measure even though many of them $(22 \%)$ failed to generate such a response with the open-ended questions. When creationist explanations were suggested, as in the closed-ended agreement measures, it appears that natural explanations, such as spontaneous generation and evolution, were seen as less viable and suppressed, at least with these populations.

Artifacts. A similar measure of belief consistency (artificialist-tocreationist) was constructed for artifact origins from the origins-agreement measure (see Table 4). Unlike the results for the animates and inanimates, the profiles of the three older age groups in both communities were very similar. With the exception of the young nonfundamentalists, a majority of each group endorsed a pure artificialist explanation for artifact origins. Young nonfundamentalist children, though, were more likely than their fundamentalist counterparts to conflate the power of God and that of the human; God, on this analysis, appeared to be treated as just another human.

In general, the percentage of pure artificialist responses increased steadily by age group, but the middle age group from the fundamentalist community provided an interesting exception. In comparison with the other fundamentalist age groups, they were more likely to endorse mixed artificialist/creationist explanations and less likely to endorse pure artificialism. This finding is in line with earlier analyses demonstrating the preferential use of creation for human origins by the middle age group (but not younger children). Together these results suggest that, unlike their younger siblings, children from the middle age groups may be confronting the issue of final cause, which addresses the question of why something might come into existence in the first place. Having recently come to the conclusion that God creates all animates (including the human) and that humans create artifacts, children from the middle age group could be struggling with the question of whether God created artifacts via human agency; therefore, both artificialism and creationism are valid. In effect, the overall pattern of developmental change suggests a U-shaped curve, with older participants and younger fundamentalists both distinguishing between the powers of God and of the human, but for different reasons. Although the younger fundamentalists appear to be precocious in their use of creation and artificialism, their accomplishment is unlikely to reflect a mature understanding of final cause.

Inanimates. For inanimate origins, a typology of belief consistency (spontaneous generation-to-creation) was constructed from the origins-agreement measure and is presented in Table 5. Comparison of the percentage of participants endorsing creationist and natural explanations for inanimate 
(spontaneous generation; see Table 5) and animate origins (evolution; see Table 3) yields several interesting findings. The spontaneous generation exemplar, "came out of the ground," was more likely to appeal as a pure natural explanation for inanimate origins, than the natural explanation, evolution, did for animate origins, especially for the older nonfundamentalists. Additionally, the percentage of pure creationist explanations is greater for the animate than for the inanimate entities for each age group in both communities.

Summary. These findings raise intriguing issues as to why creation appears to be a more compelling explanation for animate than for inanimate origins. As many have suggested, the very complexity of animates and their teleological entailments might invoke a teleo-intentional explanation (e.g., Dawkins, 1987). Relatedly, the natural explanation for animate origins, evolution, seems to be particularly unappealing with its counterintuitive emphasis on species change. On the other hand, the natural explanation for inanimate origins, spontaneous generation, appears to have considerable intuitive appeal for many participants.

Regarding the issue of explanatory coherence, these results indicate that coherent belief systems were evidenced to a greater degree in the fundamentalist communities. Mixed beliefs were less prevalent in the fundamentalist than in the nonfundamentalist communities, especially for animate entities. Moreover, a majority of fundamentalists exhibited coherent belief structures with God, alone, being responsible for the origins of both natural kinds, animate and inanimate, and humans, alone, being responsible for the origins of artifacts.

It could be argued, though, that the mixed beliefs of some nonfundamentalists' might well reflect coherent belief systems. As described earlier, some participants, in particular nonfundamentalist adults, endorsed evolution for nonhuman species while reserving creation for human origins. However, if a majority of nonfundamentalist adults had proposed such a solution then the score for evolution should be higher than that for creation in most of the mixed belief cases, given that in this study the proportion of nonhuman species exemplars to human exemplars was $2: 1$. Yet on the agreement measure (see Table 3 ) only $36 \%$ of the mixed belief cases showed this pattern. Further, theistic evolution, which is a coherent framework in which God plays a more distal role as the originator of an evolutionary process, could well have been endorsed by many of the nonfundamentalists. However, although theistic evolutionists might have expressed mixed beliefs in the open-ended (frequency) measure, they would be unlikely to have endorsed the patently biblical literalist "creationist" exemplars in the closed-ended (agreement) measures. Nonetheless, differences between measures indicate a decrease in mixed beliefs and an increase in pure creationism from the frequency to the agreement measures. This is the opposite of what would have been predicted 
if coherent theistic evolutionists had made up a significant proportion of the nonfundamentalist population.

\section{Consistency of Parent Belief, Markers of the Custom Complex, and Children's Beliefs}

The subsequent analyses focus on individual belief and the relationship between the consistency of parents' beliefs, various markers of the custom complex, and children's beliefs. Given that children in the two school communities differed on their putative beliefs about origins and related issues but not in terms of parental educational level and general interests, they were combined into one pool. The measure of parent belief-consistency is based on the closed-ended animate agreement score, described above. This particular measure is used as an indicator of parent beliefs for two reasons: more parents completed the closed-ended measure than the open-ended one, and it forced parents to explicitly consider every explanation for animate origins. It is worth noting that results using closed-ended measures were very similar to those based on the open-ended data. Thirty-nine children were excluded from these analyses as they did not have complete parent data. The remaining child sample ( $n=147)$ included 52 from the young age group (23 nonfundamentalist community; 29 fundamentalist), 51 from the middle age group (27 nonfundamentalist community; 24 fundamentalist), and 44 from the older age group (28 nonfundamentalist community; 16 fundamentalist).

To examine the thesis that consistency of parent beliefs influences the kind of environment provided for children, zero-order correlations between parent evolutionist-to-creationist consistency beliefs, children's beliefs, and the various markers of the custom complex described in the last section (see Table 1) were calculated (see Table 6). A measure of church type was also included, since this is a crude marker of the degree to which biblical literalism may have been encountered in a church setting ( 1 , no church; 2 , nonfundamentalist church; 3 , fundamentalist church); school type was included as a dichotomous variable (1, nonfundamentalist school; 2 , fundamentalist school).

Summary. Consistency of parent beliefs was related to most of the other variables in a predictable manner; for all measures the higher a score the more the environment was saturated with creation beliefs, and vice versa for evolution (see Table 6). The consistency of parent evolutionist-to-creationist beliefs correlated positively with both measures of children's creationist beliefs and negatively with both measures of children's evolutionist beliefs. Moreover, parent beliefs correlated positively with children's religious interest and likelihood of attending a fundamentalist school and church, but negatively with children's fossil expertise. Interestingly, parent beliefs were not related to children's fossil interest or dynamic adaptation endorsement. However, children's age correlated positively with children's fossil interest and 


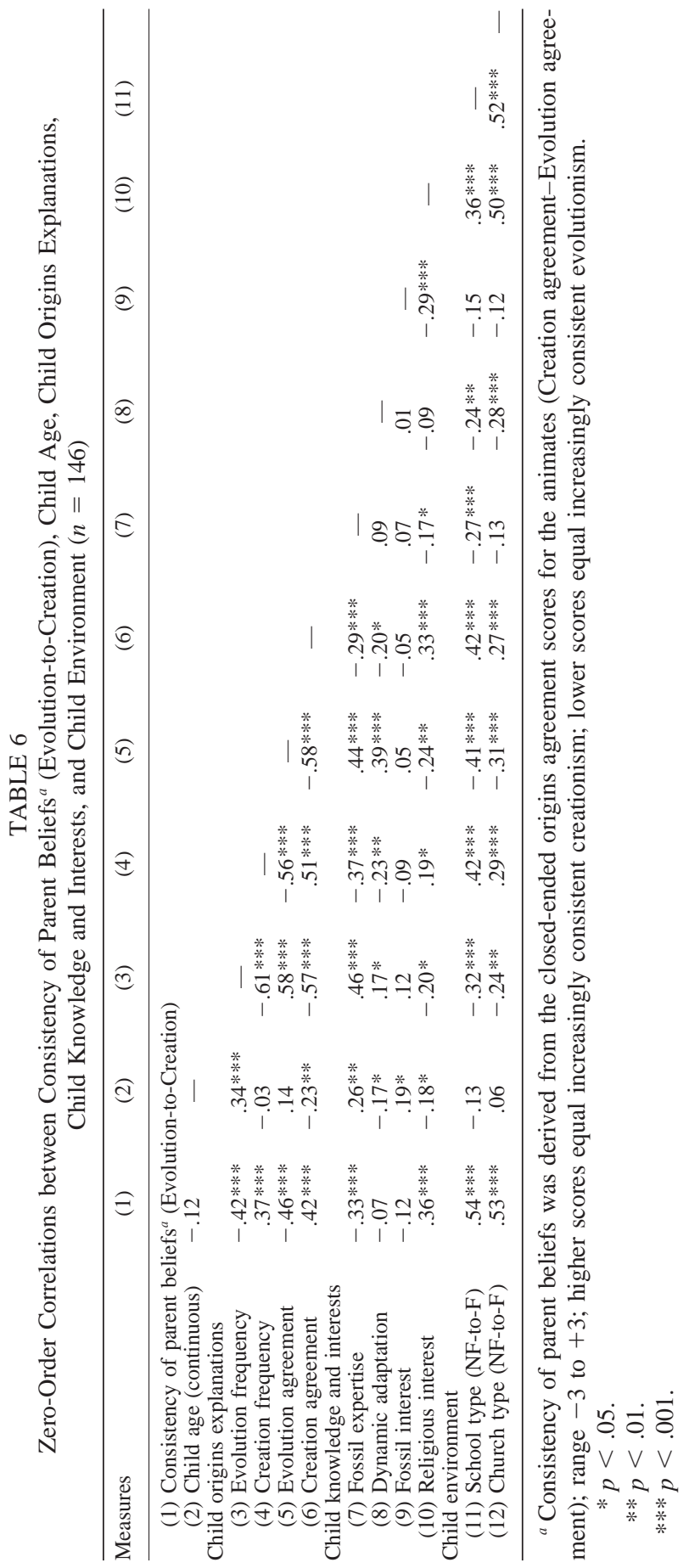


negatively with dynamic adaptation endorsement. Additionally, dynamic adaptation correlated negatively with both measures of child creationist beliefs and the likelihood of attending a fundamentalist school or church. On the other hand, dynamic adaptation was positively related to both measures of child evolutionist beliefs.

\section{Developmental Change in the Relationship Between Parent Belief, the Custom Complex, and Children's Beliefs}

If cognitive and cultural factors play an interactive role in the expression of beliefs about origins then one might predict that these factors have differential impact depending on the targeted age group. As their knowledge structures mature children's capacity to respond to social and environmental information will also change. In the next analyses the developmental patterns underlying the relationships described in the last section are clarified. Replicating and extending earlier work (Evans, 2000a), the most striking finding is that parent beliefs do not contribute directly and independently to the expression of child beliefs until children are early adolescents (10-12 years). This result is now found on both the open-ended and the closed-ended measures. Furthermore, a more detailed exploration of the effects of the culture complex now reveals subtle age-related effects, especially on the closedended measures, with parents exercising indirect influence via the environments they select for their younger children.

The above ANOVAs have demonstrated that children in different age groups differentially endorsed the various origins explanations. In the current analyses, a series of simultaneous multiple regressions is carried out to assess whether variables correlated with children's evolution and creation agreement scores (consistency of parent beliefs, fossil expertise, dynamic adaptation, religious interest, and school-type, see Table 6) impacted differentially on each age group. (Church-type was not included as this information was not available for all participants and religious interest and school type picked up most of the associated variance.) The closed-ended agreement measures are the focus of these analyses and they are summarized in Tables 7 and 8; in the following text, however, the open-ended frequency measures will be brought in as reference marks. (To save space, only results for the animates and artifacts will be reported.) Of particular theoretical interest is the independent contribution of each variable (partialing out the effects of the other variables), as indicated by the standardized regression coefficients ( $\beta \mathrm{s})$.

Animates: Evolutionary origins. For each age group, consistency of parent beliefs, fossil expertise, dynamic adaptation, religious interest, and schooltype were simultaneously regressed on children's evolution agreement scores. Although in each age group a significant portion of the variance was explained by the joint effects of these variables, the profile differed by age group (see Table 7). Notably, only in the oldest age group did parent beliefs contribute independently to the children's evolution agreement scores; in 


\section{TABLE 7}

Animates-Evolutionist Origins: Multiple Regressions on Child Evolution Agreement Scores for Three Elementary-School Age Groups (Standardized Regression Coefficients)

\begin{tabular}{lccc}
\hline & \multicolumn{3}{c}{ Age group $(\beta)$} \\
\cline { 2 - 4 } Predictors & Young & Middle & Older \\
\hline Consistency of parent beliefs & .04 & -.16 & $-.58^{* * *}$ \\
Child's fossil expertise & $.30^{*}$ & $.28^{*}$ & .09 \\
Child's dynamic adaptation score & .25 & $.40^{* *}$ & $.30^{* *}$ \\
Child's religious interests & .08 & -.11 & -.07 \\
School type (NF to F) & -.25 & .04 & -.07 \\
$R^{2}$ & $.30^{* *}$ & $.36^{* *}$ & $.71^{* * *}$ \\
\hline
\end{tabular}

Note. See Table 6.

$* p<.05$.

$* * p<.01$.

$* * * p<.001$.

this age group $71 \%$ of the variance in children's scores was explained, with children's dynamic adaptation scores $(\beta=.30)$ and parent beliefs $(\beta=-.58)$ making significant independent contributions. For the two younger age groups, children's fossil expertise $(\beta \mathrm{s}=.28-.30)$ and, in the middle age group, their dynamic adaptation scores $(\beta=.40)$ made significant independent contributions to children's evolution agreement scores.

The same variables were simultaneously regressed on children's evolution frequency scores separately for each age group. Essentially the same pattern

\section{TABLE 8}

Animates-Creationist Origins: Multiple Regressions on Child Creation Agreement Scores for Three Elementary-School Age Groups (Standardized Regression Coefficients)

\begin{tabular}{lccc}
\hline & \multicolumn{3}{c}{ Age group $(\beta)$} \\
\cline { 2 - 4 } Predictors & Young & Middle & Older \\
\hline Consistency of parent beliefs & .06 & .24 & .25 \\
Child's fossil expertise & .15 & .10 & -.24 \\
Child's dynamic adaptation score & -.17 & -.02 & -.13 \\
Child's religious interests & -.03 & $.39 * *$ & .24 \\
School type (NF to F) & $.45^{* *}$ & -.02 & .14 \\
$R^{2}$ & $.24 *$ & $.27 *$ & $.47^{* * *}$ \\
\hline
\end{tabular}

Note. See Table 6.

$* p<.05$.

$* * p<.01$.

$* * * p<.001$. 
emerged for the old age group: 67\% of the variance was explained ( $p<$ $.0001)$, with parent beliefs $(\beta=-.40 ; p<.004)$, child fossil expertise $(\beta=$ $.24 ; p<.04)$, and dynamic adaptation scores $(\beta=.30 ; p<.005)$, making significant independent contributions. For the middle age group the overall regression was not significant, but there was a trend for the young age group $\left(R^{2}=.19 ; p<.07\right)$.

Animates: Creationist origins. Next, for each age group, consistency of parent beliefs, fossil expertise, dynamic adaptation, religious interest, and school-type were simultaneously regressed on children's creation agreement scores (see Table 8 ). For the young age group, school-type $(\beta=.45)$ made a significant independent contribution to children's creation agreement scores, whereas for the middle age group only the child's religious interest had an independent effect $(\beta=.39)$. Interestingly, although all the variables jointly accounted for $47 \%$ of the variance in the older age group's scores, none made a significant independent contribution. However, school-type appears to have masked the effects of the other variables; when it was removed from the regression, the overall variance explained decreased minimally to $46 \%$ but parent beliefs $(\beta=-.31 ; p<.05)$, and child religious interest $(\beta=$ $.29 ; p<.03$ ) now made significant independent contributions.

When the same variables were simultaneously regressed on children's creation frequency scores for each age group, school type again made a significant independent contribution to the scores of the young age group $\left(R^{2}=\right.$ $.34 ; p<.0002)$, but the overall regression was not significant for the middle age group. For the older age group, $76 \%$ of the overall variance was explained with all variables in place $(p<.0001)$; significant independent contributions were made by school-type $(\beta=23 ; p<.04)$, parent beliefs $(\beta=$ $45 ; p<.0003)$, and child fossil expertise $(\beta=-.27 ; p<.007)$. Only after removing school-type from the equation did child religious interests $(\beta=$ $18 ; p<.05)$ make a significant independent contribution.

Animates: Spontaneous generation origins. Again, for each age group, consistency of parent beliefs, fossil expertise, dynamic adaptation, religious interest, and school-type were simultaneously regressed on children's spontaneous generation agreement scores. There was a significant overall regression coefficient only for the young age group, $R^{2}=.49(\mathrm{R}=.70) ; F(5$, $51)=8.8, p<.0001$ (Adjusted $R^{2}=.43$ ), with dynamic adaptation making a significant independent contribution $(\beta=.63, p<.0001)$. Similar analyses on children's spontaneous generation frequency scores revealed only a trend, and only for the young age group $\left(R^{2}=.20 ; p<.07\right)$, with school-type making a significant independent contribution $(\beta=-.34, p<.05)$. Young children who attend fundamentalist schools were less likely to endorse these ideas, whereas children who are attracted to naturalistic explanations (e.g., dynamic adaptation) were more likely to endorse spontaneous generation explanations. 
Artifacts: Creationist origins. The same regressions were carried out for the creation agreement scores for the artifacts and a significant overall regression was obtained only for the young age group, $R^{2}=.28(R=.53) ; F(5$, $51)=3.5, p<.009$ (Adjusted $\left.R^{2}=.20\right)$; significant standardized regression coefficients were obtained for school-type $(\beta=-.39, p=.02)$ and dynamic adaptation $(\beta=.34, p<.02)$. Note that school type contributed negatively to this equation, indicating that children in fundamentalist schools were unlikely to agree that artifacts were made by God. Given that none of the included variables significantly predicted the creation agreement scores of children from the middle age group, these results provide further evidence for the difference between the creationism of the young age groups and that of the middle age groups, as outlined in the above analyses.

If the younger children's partial conflation of artificialism and creationism was any indication that they were not yet attuned to final cause (creationist) arguments, as argued earlier, then it should follow that the higher their creation agreement score for artifacts the more likely they would be to endorse proximate cause arguments for animate origins (spontaneous generation) and the less likely they would be to endorse final cause arguments (creation). Correlations between the creation agreement scores for artifacts (for the young group only) and the relevant variables provide some evidence that this was the case: Creation agreement for artifacts and (1) spontaneous generation agreement for animates $(r=.27 ; p<.04)$; (2) spontaneous generation frequency for animates $(r=.32 ; p<.02)$; (3) creation agreement for animates $(n s) ;(4)$ creation frequency for animates $(r=-.32 ; p<.02)$. In the case of animates, the significant relationship for the creation-frequency measure and not for the creation-agreement measure probably indicates that the former was a more stringent test of children's understanding of creationism than the latter.

Relations between predictors. The preceding analyses give the overall impression that parent beliefs directly impacted child beliefs only in the case of the older elementary school children. However, although the effect was not direct, the environment provided by parents did appear to influence younger children's beliefs as well. Simultaneous regressions for each age group were computed with three environmental measures (school-type, church-type, and the consistency of parent beliefs) and the child knowledge and interest measures (fossil expertise, dynamic adaptation, religious interest), as predictors on each of the latter child knowledge and interest measures.

Dynamic adaptation was significantly predicted in the middle age group only $\left(R^{2}=.46 ; p<.0001\right)$, with school type $(\beta=-.29, p=.04)$, church type $(\beta=-.66, p=.0001)$, and fossil expertise $(\beta=.26, p<.03)$, as significant independent predictors. For fossil expertise, the overall regressions were significant in both the young and the old age groups $\left(R^{2} \mathrm{~s}=.29\right.$ to $.31 ; p$ 's $<.02)$; in the young age group, school-type $(\beta=-.38, p=$ 
.03) was the most significant independent predictor, whereas in the old age group, parent belief-consistency ( $\beta=-.42, p=.02$ ) was the only significant independent predictor. For religious interest, at all ages there were significant overall regressions $\left(R^{2} \mathrm{~s}=.35\right.$ to $.38 ; p$ 's $\left.<.002\right)$, with school and/or churchtype $(\beta$ 's $=-.37$ to $.58 ; p$ 's $<.02)$ contributing independently to the overall score of the two younger groups.

Although children who endorsed dynamic adaptation were more likely to be younger and to go to nonfundamentalist schools and churches, the idea of dynamic adaptation was not one that was likely to receive direct community support, unlike fossil expertise and religious interest (note the lack of a correlation between dynamic adaptation and parent beliefs in Table 6). Dynamic adaptation appears to be an idea that was constructed by children in a (nonfundamentalist) environment that facilitated, or at least failed to inhibit, naturalistic explanations involving change. Unbiased observers of the natural world are sure to be beguiled by the abundant evidence of change in nature from metamorphosis to adaptation, and analyses above have indicated that nonfundamentalist parents were more likely than fundamentalist parents to encourage such naturalistic interests (see Table 1).

Summary. The endorsement of evolutionary ideas for animate origins by children in early adolescence was largely a function of their dynamic adaptationist beliefs and fossil expertise, along with the consistency of their parents' beliefs about evolution, which together explained around $70 \%$ of the variance in preadolescents' beliefs. For their younger siblings in the early and middle elementary school years, however, parent beliefs exerted no independent effect, and fossil expertise and dynamic adaptationist beliefs made the most significant contribution. It would be a mistake to assume, however, that the latter variables functioned independently of parental beliefs, for children from fundamentalist homes and schools were less likely to be as knowledgeable about fossils or endorse the idea that acquired features could be inherited (dynamic adaptation). What appeared to be happening was that not until early adolescence were children ready to abandon creationist theories of origins and adopt a naturalistic explanation that violated their strongly held beliefs in the immutability of species. Parental beliefs in evolution presumably fostered this shift both directly, by explicitly endorsing evolution and exposing children to the evidence for evolution, such as fossils, as well as indirectly, by promoting naturalistic interests in general.

For creationist beliefs, the overall picture was somewhat similar, though in this case, attendance at a Christian fundamentalist school now played a critical role. Among the oldest children, depending on the measure, from $47 \%$ (agreement) to $67 \%$ (frequency) of the variance in the expression of creationist beliefs could be explained. This large difference between measures is another sign that the open-ended frequency measure was a more stringent indicator of a coherent creationism, whereas the closed-ended agreement measure encouraged the ad hoc espousal of creationist beliefs. 
The consistency of parent beliefs about creation and, depending on the measure, children's religious interest, contributed positively to the expression of creationist beliefs in preadolescents, whereas fossil expertise appeared to exert a negative influence. Among the two younger age groups, interest in religion contributed positively to the scores of the middle age group, whereas attendance at a fundamentalist school contributed positively to the youngest children's creation scores. That there was an effect of children's religious interest over and above that of parent belief system, suggests that, as for evolutionary ideas, child-driven values and interests played a role in the expression and coherence of these belief systems, especially in older children.

For the expression of spontaneous generationist beliefs, not surprisingly, few measures of the custom complex proved to be valid indicators. For both animate and inanimate origins, depending on the age group, fundamentalist schooling apparently inhibited the expression of spontaneous generationist explanations, which were most likely to be endorsed by young children who were already predisposed toward the kind of naturalistic argument found in dynamic adaptation.

\section{Artificialism: A Source Analog for Creationism?}

Previously it was proposed that artificialism might be a source analog for creationism. Although these studies did not specifically address this proposal, further analyses of the relationship between these two constructs do provide support: these constructs are significantly correlated even when the effects of other critical variables are partialed out of the equation. At a minimum, if one construct is an analog of the other then the two constructs should be related; if they are not related then they can hardly be analogs. Further, it is argued that initially a source analog and its target are likely to be conflated and that they become gradually disassociated as more components of the source (such as features, structural relations, etc.) are mapped on to the target. Over time the target and source should become increasingly distinct and coherent structures. This hypothesis is addressed in a developmental framework by constructing measures of coherent artificialism and creationism and assessing their relationship, while partialing out the effects of other variables that could account for this relationship.

Composite measures of coherence were constructed for artificialism and creationism by combining responses for the animates, inanimates, and artifacts for each construct in turn, using the agreement measure. Coherence was operationalized as agreement with the following propositions: (1) Artificialism: humans made the very first artifacts; humans did not make the very first animates or inanimates. (2) Creationism: God made the very first animates and inanimates; God did not make the very first artifacts. The higher the score on each construct (possible range, -3 to 3 ), the more likely the participant was to agree with each proposition.

Data from children $(n=103)$ in only the two younger age groups (5.310.3 years) were combined and used in these analyses because it is in these 
age groups that a coherent creationism appeared to be emerging. Coherent artificialism, age, school-type, and parent belief-consistency, were simultaneously regressed on children's coherent creationism scores. There was a significant overall regression coefficient, $R^{2}=.44(R=.66) ; F(4,98)=$ $19.1 ; p<.0001$ (Adjusted $R^{2}=.42$ ), with coherent artificialism $(\beta=.49$, $p<.0001)$ and school-type $(\beta=.34, p<.001)$ making significant independent contributions. In the next analysis, coherent creationism, age, schooltype, and parent belief-consistency, were simultaneously regressed on children's coherent artificialism scores. Again, there was a significant overall regression coefficient, $R^{2}=.35(R=.59) ; F(4,98)=13.1 ; p<.0001$ (Adjusted $\left.R^{2}=.32\right)$, and, in this case, coherent creationism $(\beta=.56, p<$ $.0001)$, age $(\beta=.19, p<.03)$, and parent belief-consistency $(\beta=-.19, p$ $<$.05) made significant independent contributions. Notably a child's age only contributed independent variance to the latter equation, indicating that the apparent effect of age (increasingly coherent creationism over time) was explained by the other variables.

Summary. Children who had a coherent understanding of the powers of God were also likely to have a coherent understand of the limitations of human capabilities; conversely, children who were confused about God's capabilities were also confused about human capabilities. The positive relationship between artificialism and creationism held true even when other related variables such as age and exposure to creationist beliefs, at home or at school, were partialed out of the equation (though these variables did contribute additional variance). Of course the direction of the effect is not clear from these data, but the significant relationship between artificialism and creationism does provide some support for the proposition that one may be an analog of the other.

This analysis further suggests that an analogical mapping between target and source may have bidirectional effects. In the process of differentiating from its source, the target concept may serve to further specify the nature of the source concept. For example, what might begin as a somewhat inchoate limited artificialism, with God as merely another human sharing a human's creative responsibilities, is later differentiated into two daughter concepts, coherent artificialism and coherent creationism. Exposure to creationist beliefs seems to promote this change. Initially, however, the idea that "God-makes-animals", appears to be loosely associated with the artificialist structure, almost as an ad hoc belief. Further studies involving preschoolers and additional related variables are needed to clarify the nature and direction of the effect.

\section{GENERAL DISCUSSION}

Why does it appear as if "the human brain is specifically designed to misunderstand Darwinism .. .?’' (Dawkins, 1987). On the surface, at least, Darwinian concepts seem simple and easy to grasp; their complexities are 
revealed only with more detailed scrutiny (Mayr, 1991). Dawkins (1995) claims that the reason adults subscribe to creationist explanations is that they have not yet put away "childish things," that, like young children, they are "gullible . . . credulous, ... and faith-filled." Dawkins underestimates both children and adults. Children are not sponges effortlessly absorbing all knowledge, for if they did formal education would scarcely be necessary. They are selective constructivists, rapidly assimilating ideas to the extent that they are congruent with existing knowledge structures, and rejecting others that do not fit in (Piaget, 1929). Dawkins' polemic ignores the most interesting feature of this debate: Why are creationist ideas so much more attractive than evolutionist ideas, at least in these communities? The answer is not that adults are like children, even though there are obvious continuities. As this study demonstrates, both children and adults are susceptible to creationist explanations, but adult creationism is more likely to be embedded in a complex knowledge structure. Children's earliest creationist explanations may simply reflect a "transfer of expectations" (Boyer \& Walker, 2000) from an intuitive ontology, a naive theory of mind (see Evans, 2000b).

In this study, cognitive and contextual factors appeared to play an interactive role in the dissemination of beliefs about the origins of species, suggesting a "constructive interactionism" (Wozniak \& Fischer, 1993). Early adolescents (11 to 13 years), like their parents, embraced the dominant beliefs of their community, be they creationist or evolutionist. Their younger siblings, especially those in the middle elementary school years (8 to 10 years) were more apt to be exclusively creationist, whatever their community of origin. Early elementary school children (5 to 7 years) endorsed creationism more strongly if they had been to a fundamentalist school or if they were reminded of creationist explanations, as in the forced-choice measures. Otherwise, they were likely to endorse mixed spontaneous generationist and creationist beliefs (see also Evans, 2000a). Interestingly, even when interviewers suggested evolutionary explanations, as in the forced-choice measures, children in the early to mid elementary school years still resisted such ideas.

These results indicate that in comparison with the two naturalistic explanations, creationist ideas are, indeed, far more contagious (Sperber, 1996), at least in these communities. An environment imbued with creationism, as in Christian fundamentalist school communities, or even in the case of interviewer suggestion, markedly increases the frequency of creationist responses in all age groups on all measures. In effect such environments serve to suppress or, at least, fail to facilitate, natural explanations, such as spontaneous generation or evolution. Why is the human mind (at least, the Western protestant mind) so susceptible to creationism and so comparatively resistant to naturalistic explanations for the origins of species? A more detailed examination of these data reveals that this susceptibility is a function of several factors, cognitive and contextual; there is no single explanation. 


\section{Cognitive Constraints}

The primary argument presented here is that the two staples of Western philosophical thinking, essentialism and final-cause or teleological reasoning, emerge from intuitive propensities of the human mind. Moreover, it is suggested that when these basic modes of construal (Keil, 1994) are reified in public representations such as in Western religious or philosophical traditions, they then serve to inhibit the expression of natural explanations for the origins of species.

There is increasing evidence to support the idea that the inferential reasoning capacities of the developing mind are constrained by at least three intuitive modes of construal: essentialism, teleology, and intention (see Atran, 1990; Carey, 1985; Gelman et al., 1994; Keil, 1994; Wellman, 1990; Wellman \& Gelman, 1997). As noted in the earlier discussion of Lamarckian ideas, teleology and intentionality are potentially dissociable although they are often conflated in the literature (see also Kelemen, 1999a, b). Moreover, elementary school children have been shown to differentially endorse the three modes when explaining the diverse behaviors of a range of biological kinds (Poling \& Evans, in press). In the final cause reasoning of the creationist, however, teleology and intention are linked (God's purpose) and used to explain the presence of previously nonexistent entities. Historically, according to Mayr (1982), if it had not been for the paralyzing effect of monotheistic creationism, spontaneous generation might have been the immediate precursor to evolutionary thinking, for, like evolution, it evokes naturalistic and nonteleological reasoning. The evidence presented in this study from both communities suggests that essentialism, in a specific guise, may well be an impediment to the expression of evolutionary ideas; on the other hand, the final-cause reasoning evident in a creationist account of origins might, under some circumstances, act as a catalyst for the ultimate-cause reasoning evident in evolutionary ideas.

Essentialism. The idea that species are inherently immutable was hypothesized to be a crucial factor in the attractiveness of creationist ideas and the resistance to evolutionary ideas for all children in their early-to-mid elementary school years, and for both children and adults from Christian fundamentalist communities. With creationism the essentialistic beliefs of the early elementary school years (see Gelman et al., 1994; Gelman \& Hirschfeld, 1999) are not only maintained, they are deified, at least in these Christian fundamentalist contexts.

Moreover, Mayr (1982) has proposed that an essentialistic philosophy, with its insistence on the unchanging essence or eide of each and every species, was one of the key historical factors preventing the adoption of evolutionary explanations (but see Atran, 1990, for an alternative view). Up to Darwin's time, philosophers “'considered species as natural kinds," separable by "bridgeless gaps", (Mayr, 1991, p. 41). Although commensurate with the idea that each species was specially created by God, such beliefs were 
clearly incommensurate with the idea that a species might change through adaptive processes. At a minimum such essentialistic ideas had to be challenged before evolutionary ideas could emerge. For Lamarck, it was the fossil evidence that opened his eyes to the idea that "efforts to satisfy individual needs" might lead to the gradual transformation of one life-form to another (Mayr, 1982). Similarly, Darwin's work among the diverse species of the Galapagos Islands fueled his thesis that nature functions as a selection device operating on the variation apparent in any population to produce new species (Mayr, 1982).

Nevertheless, some have argued that essentialistic constraints are never overcome; instead, what is granted essential causal power is transformed with the acceptance of evolution (e.g., Evans, 2000a; Gould, 1992; Kornblith, 1993). Such a view is more in keeping with Atran's (1990) contention that historically a strict version of essentialism was rare among naturalists (p. 84). By attempting to identify those DNA sequences that historically define a species even modern geneticists appear to be susceptible to essentialism. However, this apparent paradox could be resolved by distinguishing between explicit philosophical or religious beliefs in the immutable essence of manifest natural kinds (see Hirschfeld, 1996), which was overthrown by evolutionary ideas, versus psychological essentialism (Medin \& Ortony, 1989), an implicit and basic mode of construal that even contemporary biologists appear to endorse. Young children are likely to endorse the latter (Gelman \& Hirschfeld, 1999).

In the present study, a further piece of evidence for the crucial role of essentialism in the expression of creationist belief is the resistance to ideas about the inheritance of acquired features (dynamic adaptation) among children in fundamentalist communities. Unlike evolutionary explanations, dynamic adaptation merely suggests that the individual animals acquire new features in response to environmental pressures and that these features are then exhibited in their offspring; it does not address species change. Nonetheless, comments by Christian fundamentalist children implied that such statements were regarded with suspicion: "God made it that way, so it can't change,' was one 11-year old's rejoinder when asked if an animal could get a long neck from stretching to reach high vegetation (Evans, 2000b). This kind of response indicates that in communities where essentialism is deified, a coherent creationist will reject even the hint of a biological change. The nonfundamentalist children, in contrast, were more open to the possibility of dynamic adaptation, even though the inheritance of acquired features is scientifically incorrect.

Not surprisingly, and unlike children's fossil knowledge, children's endorsement of dynamic adaptation was unrelated to the consistency of their parents' beliefs. However, particularly in the older groups, both fossil knowledge and dynamic adaptation, independently of each other and of parent beliefs, positively predicted children's evolutionary beliefs and negatively 
predicted their creationist beliefs. This particular pattern of results indicates that these two measures, fossil knowledge and dynamic adaptation, tap different knowledge structures, yet each of them contributes to the increased expression of evolutionary explanations. Such results lend credence to the proposal that exposure to evidence that animals can change allows children to suspend their beliefs in the immutability of manifest species and shift toward an evolutionary explanation, as it apparently did for Lamarck and Darwin. However, although such evidence might be necessary, it is hardly sufficient. A key corollary would be that children should not be blinded to this evidence by a custom complex in which essentialism is not only reified but also deified. In environments in which creationist beliefs are underdetermined, children apparently construct their own evolutionary explanations using as analogies sources present in the natural context (Evans, 2000a; Hatano \& Inagaki, 1996; Samarapungavan \& Wiers, 1997).

Children in the Christian fundamentalist schools had access to the same science textbooks as the public-school children and they were also taught about fossils and natural history but they were neither as interested in nor as knowledgeable about fossils, ${ }^{3}$ and they actively resisted any idea that animals could change. One 12-year old child reported, "Sometimes the [school] books say ... this guy named Derwin or something has a theory, but the teachers say the theories that disagree with the Bible are not true. His theories are about how some animals changed'' (Evans, 2000b).

Final cause reasoning. Earlier it was proposed that the age-related shift to the exclusive creationism of the middle elementary school years (8- to 10 -year-olds) came about because children of this age were beginning to contemplate existential themes such as those of existence and final cause. Questions about the origins of "the very first X" would make little sense to younger children who appear to believe in a static and unchanging world in which species always existed. Once children realize that entities were previously nonexistent the issue of original design is raised and the necessity for a final cause or teleological argument (Why are they here? What are they for?) becomes apparent (Dennett, 1995; Kelemen, 1999a, b). Children's mastery of the final cause argument of a creationist explanation may, in turn, pave the way for their later acceptance of evolution. The evidence to support this proposal in the present study is derived from two sources: the fate of spontaneous generation explanations, and the nature of the creationism of the 8- to 10-year-old nonfundamentalist children, which contrasts with that of the younger and older age groups.

Creationist explanations for animate origins in this study seemed to drive

\footnotetext{
${ }^{3}$ It should be noted, however, that the measure of fossil knowledge used in this study would be invalid from the standpoint of creationist theory, according to which, for example, dinosaurs and humans lived at the same time. Therefore children exposed to creationist theory would be unlikely to obtain high scores on the measure of fossil knowledge.
} 
spontaneous generationist arguments underground. Spontaneous generation was much less likely to be endorsed in fundamentalist communities, and when creationism was suggested, as in the closed-ended questions, spontaneous generation was endorsed less frequently in nonfundamentalist communities as well. The reason for the overpowering effect of creationism in this case is unlikely to be the creationist compatibility with essentialism, as spontaneous generation arguments are also compatible with essentialistic beliefs. Spontaneous generationist explanations, it is contended, yield proximate cause arguments only, characterized by the use of immediately prior (spontaneous appearance) or mechanistic causes (e.g., birth, growth) to explain the origins of animate entities. Unlike creationism, such arguments do not address the issue of how a particular living kind comes into being in the first place. In this respect spontaneous generation fails as a final cause explanation $^{4}$ for the origins of species. Once children appreciate the existential nuances of the origins question they appear to reject spontaneous generation in favor of a creationist explanation.

Among nonfundamentalists, a consistent creationism was more likely to be found in the middle elementary school years. Moreover, on most measures of creationism, nonfundamentalist 8- to 10 -year-olds were indistinguishable from their fundamentalist counterparts. More revealingly, when asked about the origins of artifacts, the younger nonfundamentalists (5-7 years) were the most likely of all participants to endorse creationist explanations. These findings are consistent with Piaget's thesis that when children initially invoke God, they conflate God with human (1929; Evans, 2000a). However, children are also capable of distinguishing between the powers of God and humans, in that they know that humans cannot make natural kinds (see also, Gelman \& Kremer, 1991; Petrovich, 1999), yet God can. The differences between the two age groups suggest that the younger children have yet to grasp the special and purposeful nature of God's powers; in fact, their facile espousal of creationist arguments seems merely to represent the initial adoption of an ad hoc belief (Keil, 1998). The increased sensitivity to the complex nuances of a creationist argument by the middle nonfundamentalist age group (8- to 10-year-olds) was evident on several measures. These findings indicate that a coherent knowledge structure is emerging in which the existential question is grasped and God and humans have clearly differentiated powers. More recent studies involving preschool and young elementary school children lend further support to this line of reasoning (Evans \& Gelman, 2001; Evans, Poling, \& Mull, 2001).

\footnotetext{
${ }^{4}$ Interestingly, animate and inanimate entities seem to be treated differently in this study, with creationist arguments more likely to be applied to the former and spontaneous generation to the latter (at least by nonfundamentalists). It has long been suggested that there is something about animate entities, their apparent design, that invites the artifact analogy; if something is designed, there must be a designer (Dawkins, 1987).
} 
Summary. A crucial feature of the creationist worldview is that of final cause, specifically, God's purpose. In contrast, it has been argued that modern science does not make any claims about final causes as its activities are limited to an investigation of the mechanisms underlying secondary or proximate causes (Root-Bernstein, 1984; Shapin, 1996). Mayr (1985), however, disagrees, contending that unlike the physical sciences and indeed the rest of biology, evolutionary biology is not concerned with proximate causes. Ultimate causes are to evolutionists what final causes are to creationists: both answer the question of why something came into existence in the first place. Ultimate causes, however, should not evoke the teleological or purposeful overtones of final causes, for they are purposeless teleonomic naturalistic causes (Mayr, 1982, 1985).

Based on results from the present studies, the existence of two distinct structures underlying an everyday biological understanding can be hypothesized. The earliest structure is a proximate-cause biology, followed by a lateremerging structure involving an ultimate-cause evolutionary biology. A proximate-cause biology is consistent with an essentialistic belief in a static and unchanging world, whereas an ultimate-cause biology acknowledges the causal role of the environment in adaptive change. The latter is characterized, initially, by the use of nonintentional but teleological explanations (e.g., the inheritance of acquired features - adaptive change) and later by apparently goal-directed (teleonomic) ultimate-cause explanations (Darwinian). Seen in these particular communities is an apparent explanatory void in natural explanations for species origins between proximate cause spontaneous generation explanations and ultimate cause evolutionary explanations; a teleointentional creationist explanation seems to fills the gap. The most parsimonious explanation for this void is that in these populations an evolutionary biology gains explanatory power from a creationist explanation. In short, before conceiving of a nonintentional biological purpose for biological origins, that is adaptive change, species origins are first conceptualized in terms of the needs and purposes of an intentional being: God.

\section{Contextual Constraints}

It is important to note that the members of the two school communities highlighted in this study, Christian fundamentalist and nonfundamentalist, did not differ on a number of dimensions, such as the educational level of the parents and children's and parents' interests in music and sports (for example). The modal response of members of the communities did differ, however, on several benchmark variables: religious interest, fossil expertise, and beliefs in the inheritance of acquired features (dynamic adaptation), which were a sample representing the broader custom complex. Moreover, a measure of the consistency of parent beliefs, evolutionist-to-creationist, appeared to be a valid indicator of the degree to which children's environments were saturated with the core beliefs of the particular community. Nev- 
ertheless, it was only for those children in the oldest age group that the consistency of parent beliefs proved to be a direct indicator of children's beliefs. The younger children endorsed creationist (or spontaneous generationist) beliefs regardless of the prevailing belief systems of their communities. Nonetheless, parents did influence the expression of even their younger children's beliefs by restricting the range of environments to which children were exposed.

A core element in a constructive interactionist position is the notion of variability. Although traditional developmental research characterizes children of specific ages as being in one or another stage of development, a focused analysis is likely to reveal that children of the same age are almost never uniform in their responses; often a single child demonstrates variability even when solving the same task twice (Siegler, 1996). As is evident in this study, custom complexes, too, vary in the degree to which they value and shape different behaviors and beliefs (e.g., Gardner, 1995; Miller, 1997, 1999; Shweder et al., 1997). When the emphasis is placed on the average response of a particular age group or cultural group this variability is necessarily downplayed. However, the notion of variability is a key element in explaining cognitive growth or change (Siegler, 1994; Thelen \& Smith, 1994). Certain responses are more likely to be selected as appropriate adaptations to local conditions, thus initiating a change in overall response pattern.

This variation was exploited in this study with a focus on the factors related to the expression of individual belief. Such an approach challenges the idea that custom complexes exhibit uniformity in their belief systems, even when modal responses might differ between complexes (e.g., D'Andrade, 1990). As described earlier, elementary school children have at their disposal a variety of modes of construal that constrain their understanding of the natural and intentional worlds. By selecting a particular range of learning opportunities, the custom complex can restrain or expand the expression of these intuitive explanatory modes. The sanctioning of interests in religion or of natural history, for instance, augments these intuitive propensities, which then undergird the emergence of more sophisticated capacities to engage in religious or scientific dialogs concerning the origins of species.

\section{Theoretical Implications: The Natural History of a Belief}

(and Its Explanatory Coherence)

Though they may disagree about the mechanisms, researchers operating at the interface between anthropology and psychology generally agree that knowledge structures emerge from the interaction between social and cognitive factors (e.g., Cole, 1996; Miller, 1999; Rogoff, 1990; Shore, 1996; Shweder et al., 1997; Sperber, 1996; Strauss \& Quinn, 1997). Analogical reasoning in a metaphorical guise is embedded in the social context in a variety of narrative forms such as ritual, literature, art, and comedy (Holyoak \& Thagard, 1995; Shore, 1996). This metaphorical mode of communica- 
tion potentially provides a powerful medium for the transmission of beliefs as it is effective, generative, and indirect (Holyoak \& Thagard, 1995). In this paper, several analogies were proposed to help explain the source of three different beliefs about the origins of species. The findings indicated that those beliefs were transmitted to the extent that they were interpretable by the receiver, as well as the degree to which they were instantiated and interpreted by the custom complex (Sperber, 1996). A feature of this transmission was that the original beliefs became transformed in the process; mental representations of a belief were not isomorphic copies of their public representations (Shore, 1996; Sperber, 1996; Strauss and Quinn, 1997).

In the case of the creation story, its public representation, as portrayed in the Book of Genesis, differed quite dramatically from its representation in the minds of individuals. For many of the youngest children, especially those in the nonfundamentalist community, creationism in the form of "God made it" seemed merely to be an ad hoc belief with little explanatory value. At the other extreme, for many in the Christian fundamentalist community, creationism was a coherent belief structure in which animate entities were imbued with a God-given unchanging essence and purpose. Moreover, for the coherent creationist, inanimate entities were also God-created, whereas artifacts were made only by humans.

Holyoak and Thagard (1995) argue that when a source analog is matched to a target a new schema is formed from the mapping between the two relational structures. As described earlier, such a mechanism could explain the emergence of a creationist belief: In its source analogy, a naive intentional psychology, humans are not ordinarily credited with the capacity to create animals, thus a new schema is formed in which a supernatural human, God, takes on that role. This alternative causal structure (Rosengren \& Hickling, 2000) provides the basis for new inductive inferences. Such conjectures fit into an emerging paradigm on the cognitive basis of religion in which it is argued that everyday cognitive biases not only constrain the expression of religious belief but are central to its pervasiveness (Barrett, 1998; Barrett \& Keil, 1996; Boyer, 1993; Lawson \& McCauley, 1990)

The relationship between the expression of an evolutionary belief and specific kinds of natural history knowledge appears to be fixed, in part, by the explanatory potential (Thagard, 1989) as well as the coherence of the associated natural history knowledge structure (see also Linn \& Songer, 1993). For example, a reasonably rigorous understanding of fossils and of adaptation entails not only the recognition of the pivotal role of environmental variation in biological change, called here dynamic adaptation (Evans, 2000b), but also the recognition that species are limited spatio-temporal entities. Such an understanding, it has been argued, is a necessary corollary of an evolutionary belief. In contrast, creationists (and younger elementary school children) are more likely to endorse static adaptation (Evans, 2000b), in which biological features are viewed as fixed adaptations to unchanging envi- 
ronments. In both cases biological features are seen as functional, but only for static adaptationists is that function compatible with derived essentialist notions that manifest species are uniquely designed to fit specific environments.

Initially, children from nonfundamentalist communities seemed responsive to dynamic adaptationist ideas, but without linking this mechanism to evolutionary change. However, among the older children both dynamic adaptation and fossil knowledge were positively associated with the expression of evolutionist explanations (and negatively associated with creationism). For some, of course, this pre-Darwinian (perhaps Lamarckian) version of evolutionary origins segues into a Darwinian structure, which requires, at minimum, a shift to population thinking (e.g., Mayr, 1984; Thagard, 1989). It is quite possible, however, that there is more than one route to an evolutionary explanation (see Evans, 2000a). Complex spontaneous generationist explanations, such as those described earlier and those found in research with Dutch schoolchildren (Samarapungavan \& Wiers, 1997), may, in certain contexts, yield pre-Darwinian evolutionary explanations. Certainly, the spontaneous generationist response of the 10-year-old described in the Introduction, suggests that he was on the verge of some type of evolutionary explanation.

Why is evolutionary change so difficult to contemplate, whereas intuitive notions of breeding are comparatively so easy to grasp? The answer probably lies in the extent to which variation is allowed in a kind. For creationists, limited deviation from an ideal form, revealed, for instance, in the black and white varieties of a particular kind of moth found in industrial England or in developmental change, are thought to be part of God's plan (Morris \& Parker, 1982). Such deviations are perfectly compatible with essentialistic beliefs in the immutability of kinds, provided they are confined to visible commonsense species: "interbreeding morpho-geographic communities of organisms" (Atran, 1990, p. 259). However, as is true for breeding programs with contemporary species, the boundaries between manifest kinds should not be violated, for they are seen as bridgeless gaps (Mayr, 1991, p. 41). The sterile mule is a warning of what might happen with such attempts. The transformation of one essential kind into another is considered to be unnatural; indeed for creationists (or, for that matter, young children) it can be accomplished only by a magician or artificer, such as Satan (Kehoe, 1995). For an evolutionist, however, the commonsense understanding of species boundaries is abandoned and replaced by a view of species as temporary spatio-temporal constructs, with boundaries that can be transgressed (Atran, 1990). The current data attest to the difficulty of these ideas, for such cognitive biases are not easily forsaken.

Between the ad hoc and coherent beliefs about the origins of species, there were a variety of mixed beliefs. Several nonfundamentalists, in particular, dealt with these incommensurable belief systems by assigning evolutionary explanations to nonhuman species, only, and retaining creationism for human 
origins. Even Wallace, the codiscoverer of evolutionary theory, stopped short of applying this theory to human origins (Mayr, 1982). Nonetheless, as can be seen from the typology of these belief systems, there must have been other kinds of mixed beliefs, suggesting that in many cases neither belief system was especially coherent. Anecdotally, several parents conveyed their disquiet with the choice: "One way to avoid two completely contradictory theories is not to think about them;', 'I don't know what to believe, I just want my kids to go to heaven"' (Evans, 2000b).

\section{CONCLUSION}

In this account of the epidemiology of beliefs (Sperber, 1996) about the origins of species, neither the custom complex nor individual constructivist capacities appeared to be privileged. Sperber's synthesis of anthropological and psychological approaches to the representation of belief provides an apt epidemiological framework for modeling the spread of beliefs in a population (Sperber, 1996). In this synthesis, mental representations that result from the interpretation and internalization of public or cultural representations are termed reflective explanations, whereas representations that are largely the product of an inferential reasoning process are termed intuitive. The above analysis of the ideological dispute suggests that for adults, at least, both reflective and intuitive explanations play a role in the stabilization of creationist and evolutionist ideas in the population. What about children? From an epidemiological perspective, children born into a world of preexisting public representations would not be able to avail themselves of such representations unless they already possessed some system of analogous intuitive beliefs (Sperber, 1996, p. 79). As evidence for this position, the studies just reported suggest that the capacity to access the source analogies present in the natural and social environments is constrained by the inductive potential of children's intuitive ontologies.

A unique feature of this study is that factors related to the acquisition of these diverse belief systems were able to be disassociated from other potentially influential aspects of the custom complex. The coherence of parent creationist and evolutionist belief systems was associated with child environments that were relatively more saturated with the customs and values of the respective custom complexes, which then appear to have served to constrain the expression of children's beliefs. At their extreme, though, the coherence of these systems and the inductive inferences they engendered rendered individuals resistant to contradictory evidence (see also Chinn \& Brewer, 2000; Holyoak \& Thagard, 1995).

What might happen if children were reared in custom complexes where, in contrast to Western thought, species were seen as seamlessly interconnected, such as Buddhist philosophies? The present findings suggest that younger children exhibit variable naturalistic or intentional modes of con- 
strual and the custom complex privileges the construction of the culturally sanctioned mode and inhibits the construction of the less-preferred mode. More complex forms of reasoning emerge as consequence of this interaction: they are neither preprogrammed nor simply derived from the social environment. Although psychological essentialism might be a universal (e.g., Atran, 1990; Gelman \& Hirschfeld, 1999; Medin \& Ortony, 1989), only in those environments in which essentialism is deified is a coherent creationism likely to be exhibited by children. Moreover, only in contexts in which intuitive essentialistic beliefs in the stability of manifest species are challenged would coherent evolutionary beliefs be evident. The contexts sampled in this study varied in their endorsement of creationism; nevertheless, even children in the less saturated contexts were exposed to creationism to a degree that might not be found in other cultural settings. Absent that particular environment, naturalistic modes of explanation for the origins of species might then predominate. It is the interaction between cognitive and contextual factors that serves to ensure the existence of culturally valued domains of competence in subsequent generations (Gardner, 1995).

\section{APPENDIX: MEASURES OF CHILDREN'S NATURAL HISTORY KNOWLEDGE}

How much do you agree with the following on a scale of 1-4: (1) Strongly Disagree,

(2) Disagree, (3) Agree, (4) Strongly Agree.

Fossil Expertise

Dinosaurs and people used to live on the earth at the same time.

A Petoskey stone is a coral that turned into rock, a long time ago.

A geode is a kind of rock with crystals in it.

The pteranodon was not a real dinosaur, it was a flying lizard.

If animals or plants gradually turn into stone, they become fossils.

Petrified wood is wood that has been kept under water for a long time.

If the earth changes a lot some animals might become extinct.

All rocks with strange designs on them are fossils.

A long long time ago, there was no life on earth.

Dynamic Adaptation

If an animal swims a lot it might get webbed feet; its babies will have webbed feet, too.

If an animal breaks its leg and it heals with a big lump; its babies will be born with legs with

big lumps on them, too.

If an animal stretches up into the tree to get food it might get a long neck; its babies will have long necks, too.

\section{REFERENCES}

Almquist, A. J., \& Cronin, J. E. (1988). Fact, fancy and myth on human evolution. Current Anthropology, 29(3), 520-522.

Atran, S. (1990). Cognitive foundations of natural history: Towards an anthropology of science. Cambridge: Cambridge University Press. 
Barrett, J. L. (1998). Cognitive constraints on Hindu concepts of the divine. Journal for the Scientific Study of Religion, 37(4), 608-619.

Barrett, J. L., \& Keil, F. C. (1996). Conceptualizing a non-natural entity: Anthropomorphism in God concepts. Cognitive Psychology, 31, 219-247.

Bishop, B. A., \& Anderson, C. W. (1990). Student conceptions of natural selection and its role in evolution. Journal of Research in Science Teaching, 27, 415-428.

Boyer, P. (1993). The naturalness of religious ideas: Outline of a cognitive theory of religion. Los Angeles/Berkeley: University of California Press.

Boyer, P., \& Walker, S. (2000). Intuitive ontology and cultural input in the acquisition of religious concepts. In K. Rosengren, C. Johnson, \& P. Harris (Eds.), Imagining the impossible: The development of magical, scientific, and religious thinking in contemporary society. Cambridge: Cambridge University Press.

Carey, S. (1985). Conceptual change in childhood. Cambridge, MA: MIT Press.

Cavanaugh, M. A. (1985). Scientific creationism and rationality. Nature, 315, 185-189.

Chinn, C. A., \& Brewer, W. F. (2000). Knowledge change in science, religion, and magic. In K. Rosengren, C. Johnson, \& P. Harris (Eds.), Imagining the impossible: The development of magical, scientific, and religious thinking in contemporary society. Cambridge: Cambridge University Press.

Cole, M. (1996). Cultural psychology: A once and future discipline. Cambridge, MA: Belknap Press.

D'Andrade, R. (1990). Some propositions about the relations between culture and human cognition. In J. W. Stigler, R. A. Shewder, \& G. Herdt (Eds.), Cultural psychology: Essays on comparative human development (pp. 48-65). Cambridge, UK: Cambridge University Press.

Dawkins, R. (1987). The blind watchmaker. New York: Norton.

Dawkins, R. (1995). Putting away childish things. Skeptical Inquirer, 19(1), 31-36.

Dennett, D. C. (1987). The intentional stance. Cambridge, MA: MIT Press.

Dennett, D. C. (1995). Darwin's dangerous idea: Evolution and the meanings of life. New York: Touchstone.

Evans, E. M. (2000a). The emergence of beliefs about the origins of species in school-age children. Merrill-Palmer Quarterly, 46, 19-52.

Evans, E. M. (2000b). Beyond Scopes: Why creationism is here to stay. In K. Rosengren, C. Johnson, \& P. Harris (Eds.), Imagining the impossible: The development of magical, scientific, and religious thinking in contemporary society (pp. 305-333). Cambridge: Cambridge University Press.

Evans, E. M., \& Gelman, S. A. (2001). Revisiting the argument from design: Final cause reasoning in young children and adults. In preparation.

Evans, E. M., Poling, D., \& Mull, M. (2001). Confronting the existential questions: Children's understanding of death and origins. Paper presented at the Biennial Meeting of the Society for Research in Child Development, Minneapolis, MN.

Ferrari, M., \& Chi, M. T. H. (1998). The nature of naive explanations of natural selection. International Journal of Science Education, 20, 1231-1256.

Gardner, H. (1995). The development of competence in culturally defined domains: A preliminary framework. In The culture and psychology reader (pp. 222-244). New York: New York University Press.

Gelman, S. A., Coley, J. D., \& Gottfried, G. M. (1994). Essentialist beliefs in children: The acquisition of concepts and theories. In L. A. Hirschfeld \& S. A. Gelman (Eds.), Mapping the mind: Domain specificity in cognition and culture (pp. 341-366). Cambridge: Cambridge University Press. 
Gelman, S. A., \& Hirschfeld, L. A. (1999). How biological is essentialism? In D. L. Medin \& S. Atran (Eds.), Folkbiology (pp. 403-447). Cambridge, MA: The MIT Press.

Gelman, S. A., \& Kremer, K. E. (1991). Understanding natural cause: Children's explanations of how objects and their properties originate. Child Development, 62, 396-414.

Gentner, D., \& Rattermann, M. J. (1991). Language and the career of similarity. In S. A. Gelman \& J. P. Byrnes (Eds.), Perspectives on language and thought (pp. 225-227). Cambridge: Cambridge University Press.

Godfrey, L. R. (1984). Scientific creationism: The art of distortion. In A. Montague (Ed.), Science and creationism. New York: OUP.

Goswami, U., Leevers, H., Pressley, S., \& Wheelwright, S. (1998). Causal reasoning about pairs of relations and analogical reasoning in young children. British Journal of Developmental Psychology, 16, 553-569.

Gould, S. J. (1992). What is a species? Discover, 13, 40-44.

Gould, S. J. (1999). A division of worms: The use and disuse of Lamarck. Natural History, 108, 18-22.

Greene, E. D. (1990). The logic of university students' misunderstanding of natural selection. Journal of Research in Science Teaching, 27, 875-885.

Guthrie, S. E. (1993). Faces in the clouds: A new theory of religion. New York: Oxford University Press.

Harrold, F. B., Eve, R. A., \& Goede, G. C. d. (1995). Cult archeology and creationism in the 1990s and beyond. In F. B. Harrold \& R. A. Eve (Eds.), Cult archeology and creationism: Understanding pseudoscientific beliefs about the past. Iowa City: University of Iowa.

Hatano, G., \& Inagaki, K. (1996). Cognitive and cultural factors in the acquisition of intuitive biology. In D. R. Olson (Ed.), Handbook of psychology in education: New models of learning, teaching, and schooling. Cambridge, MA: Blackwell.

Hirschfeld, L. A. (1996). Race in the making: Cognition, culture, and the child's construction of human kinds. Cambridge, MA: MIT Press.

Holyoak, K. J., \& Thagard, P. (1995). Mental leaps: Analogy in creative thought. Cambridge, MA: MIT Press.

Kehoe, A. B. (1995). Scientific creationism: World view, not science. In F. B. Harrold \& R. A. Eve (Eds.), Cult archeology and creationism: Understanding pseudoscientific beliefs about the past (pp. 11-20). Iowa City: University of Iowa Press.

Keil, F. C. (1989). Concepts, kinds and conceptual development. Cambridge, MA: MIT Press.

Keil, F. C. (1994). The birth and nurturance of concepts by domains: The origins of concepts of living things. In L. A. Hirschfeld \& S. A. Gelman (Eds.), Mapping the mind: Domain specificity in cognition and culture (pp. 234-254). Cambridge: CUP.

Keil, F. C. (1998). Cognitive science and the origins of thought and knowledge. In W. Damon \& R. M. Lerner (Eds.), Theoretical models of human development: Handbook of child psychology (5th ed., Vol. 1, pp. 341-414). New York: Wiley.

Kelemen, D. (1999a). The scope of teleological thinking in preschool children. Cognition, 70, 241-272.

Kelemen, D. (1999b). Why are rocks pointy? Children's preference for teleological explanations of the natural world. Developmental Psychology, 35, 1440-1452.

Keltner, D., \& Robinson, R. J. (1996). Extremism, power, and the imagined basis of social conflict. Current Directions in Psychological Science, 5, 101-105.

Kornblith, H. (1993). Inductive inference and its natural ground: An essay in naturalistic epistemology. Cambridge, MA: MIT Press. 
Lawson, E. T., \& McCauley, R. N. (1990). Rethinking religion: Connecting cognition and culture. Cambridge, UK: CUP.

Linn, M. C., \& Songer, N. B. (1993). How do students make sense of science? Merrill-Palmer Quarterly, 39, 47-73.

Mayr, E. (1982). The growth of biological thought: Diversity, evolution and inheritance. Cambridge, MA: Harvard University Press.

Mayr, E. (1984). Typological versus population thinking. In E. Sober (Ed.), Conceptual issues in evolutionary biology (pp. 14-17). Cambridge, MA: MIT Press.

Mayr, E. (1985). How biology differs from the physical sciences. In D. J. Depew \& B. H. Weber (Eds.), Evolution at a crossroads: The new biology and the new philosophy of science (pp. 43-63). Cambridge. MA: MIT Press.

Mayr, E. (1991). One long argument: Charles Darwin and the genesis of modern evolutionary thought. Cambridge, MA: Harvard University Press.

Mayr, E. (1997). This is biology: The science of the living world. Cambridge, MA: Belknap/ Harvard.

Medin, D., \& Ortony, A. (1989). Comments on Part 1: Psychological essentialism. In S. Vosniadou \& A. Ortony (Eds.), Similarity and analogical reasoning (pp. 179-193). Cambridge, UK: Cambridge University Press.

Miller, J. D. (1987). The scientifically illiterate. American Demographics, 9(6), 26-31.

Miller, J. G. (1997). Theoretical issues in cultural psychology. In J. W. Berry, Y. H. Poortinga, \& J. Pandey (Eds.), Handbook of cross-cultural psychology (Vol. 1, pp. 85-128). Boston: Allyn \& Bacon.

Miller, J. G. (1999). Cultural psychology: Implications for basic psychological theory. Psychological Science, 10, 85-91.

Morris, H. M., \& Parker, G. E. (1982). What is creation science. El Cajon, CA. Master Books.

Numbers, R. L. (1992). The creationists: The evolution of scientific creationism. New York: Knopf.

Petrovich, O. (1999). Preschool children's understanding of the dichotomy between the natural and the artificial. Psychological Reports, 84, 3-27.

Piaget, J. (1929). The child's conception of the world (Joan and Andrew Tomlinson, Trans.). Totowa, NJ: Rowman \& Allanhead.

Poling, D. A., \& Evans, E. M. (in press). Why do birds of a feather flock together? Developmental change in the use of multiple explanations: Intention, teleology, essentialism. British Journal of Developmental Psychology.

Roger, J. (1986). The mechanistic conception of life. In D. C. Lindberg \& R. L. Numbers (Eds.), God \& nature: Historical essays on the encounter between Christianity and science (pp. 277-295). Berkeley and Los Angeles: University of California Press.

Rogoff, B. (1990). Apprenticeship in thinking: Cognitive development in social context. New York: Oxford University Press.

Root-Bernstein, R. (1984). On defining a scientific theory: Creationism considered. In A. Montagu (Ed.), Science and creationism (pp. 64-93). New York: OUP.

Rosengren, K. S., \& Hickling, A. K. (2000). Metamorphosis and magic: The development of children's thinking about possible events and plausible mechanisms. In K. Rosengren, C. Johnson, \& P. Harris (Eds.), Imagining the impossible: The development of magical, scientific, and religious thinking in contemporary society . Cambridge: CUP.

Samarapungavan, A., \& Wiers, R. W. (1997). Children's thoughts on the origin of species: A study of explanatory coherence. Cognitive Science, 21, 147-177.

Shapin, S. (1996). The scientific revolution. Chicago: University of Chicago Press. 
Shore, B. (1996). Culture in mind: Cognition, culture, and the problem of meaning. Oxford: Oxford University Press.

Shweder, R. A., Goodnow, J., Hatano, G., LeVine, R. A., Markus, H., \& Miller, P. (1997). The cultural psychology of development: One mind, many mentalities. In W. Damon \& R. M. Lerner (Eds.), Theoretical models of human development: Handbook of child psychology (5th ed., Vol. 1, pp. 865-937). New York: Wiley.

Siegler, R. S. (1994). Cognitive variability: A key to understanding cognitive development. Current Directions in Psychological Science, 3(1), 1-4.

Siegler, R. S. (1996). Emerging minds: The process of change in children's thinking. Oxford, UK: Oxford University Press.

Sperber, D. (1996). Explaining culture: A naturalistic approach. Oxford, UK: Blackwell.

Springer, K., \& Keil, F. C. (1989). On the development of biologically specific beliefs: The case of inheritance. Child Development, 60, 637-648.

Strauss, C., \& Quinn, N. (1997). A cognitive theory of cultural meaning. Cambridge: Cambridge University Press.

Thagard, P. (1989). Explanatory coherence. Behavioral and Brain Science, 12, 435-502.

Thelen, E., \& Smith, L. (1994). A dynamic systems approach to the development of cognition and action. Cambridge: MIT Press.

Wellman, H. M. (1990). The child's theory of mind. Cambridge, MA: The MIT Press.

Wellman, H. M., \& Gelman, S. A. (1997). Knowledge acquisition in foundational domains. In W. Damon (Series Ed.) \& D. Kuhn \& R. Siegler (Vol. Eds.), Handbook of child psychology: Cognition, perception and language (5th ed., Vol. 2) New York: Wiley.

Whitcomb, J. C. (1972). The early earth: An introduction to biblical creationism. Grand Rapids, MI: Baker Book House.

Wozniak, R. H., \& Fischer, K. W. (1993). Development in context: An introduction. In R. H. Wozniak \& K. W. Fischer (Eds.), Development in context: Acting and thinking in specific environments (pp. xi-xvi). Hillsdale, NJ: LEA.

Accepted May 4, 2000 